\title{
التلوث البيئي وضرورة التوعية البيئية
}

م. نوفل نعمان إبراهيم

جامعة بغداد/ كلية الآداب إنمي

قسم علم الاجتماع
أ. أ. د. ميادة أحمد عبد الرحمن

جامعة بغاد/ كلية الآداب

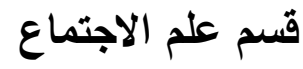

\section{(مُلَخَّصُ البَحثث)}

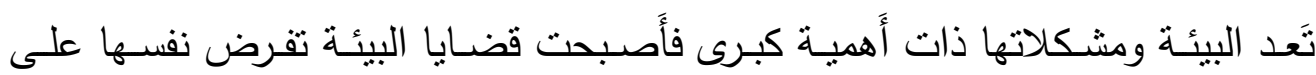

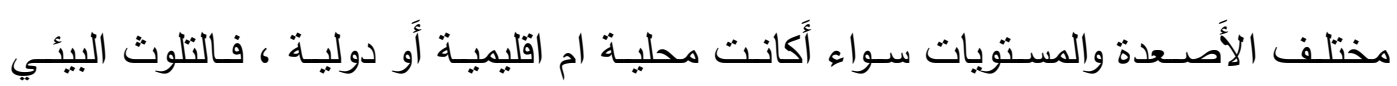
ومخاطره لا يتوقف عند حدود الدولة المسببة له فحسب بل يمتد نأثيره لباقي الدول.

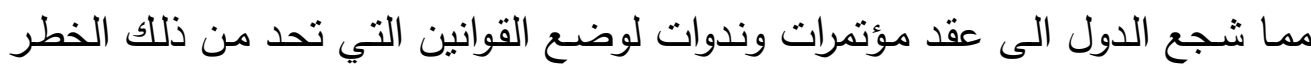

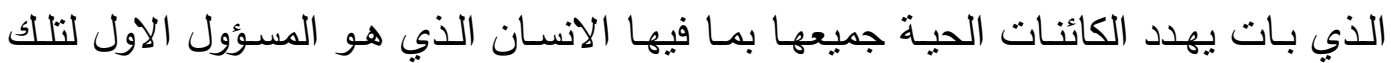

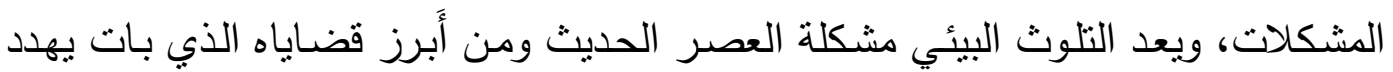

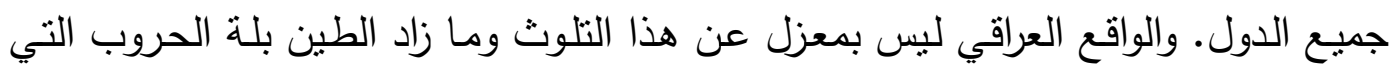

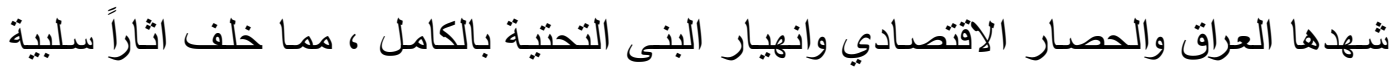

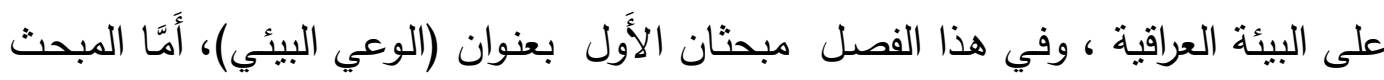
الثاني (التتمية والوعي البيئي). الكلمات المفتاحية: التلوث، البيئة، الوعي، التوعية، الإنسان المبحث الاول: عناصر الدراسة ومكوناتها اولاً: مشكلة الدراسة

تعاظم دور المؤسسة التربوية بشكل بارز بحكم كونها إحدى المصادر الاساسية التي

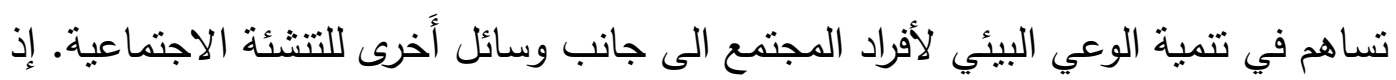

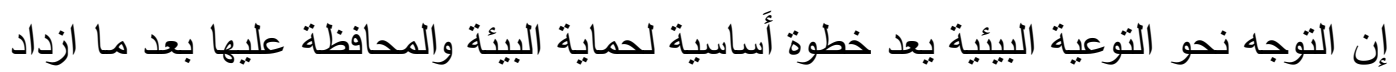

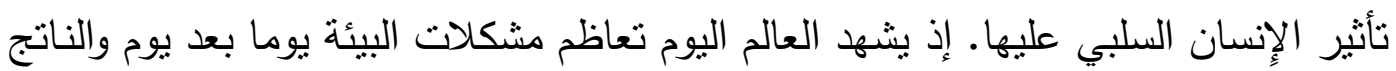
من تزايد النشاطات البشرية التي تتجه الى الاستغلال المستمر للموارد البيئية بحجة التنمية لئية متجاهلين الاثار السلبية الناتجة عن ذللك. فلم بعد دورها مقتصرا على تلقين التنلاميذ المواد الدراسية فحسب وآنما أَصبحت مسؤولة عن تبصير التلاميذ بالمشاكل التي يعانيها المجتمع وإيجاد حلول لها التي منها التلوث البيئي

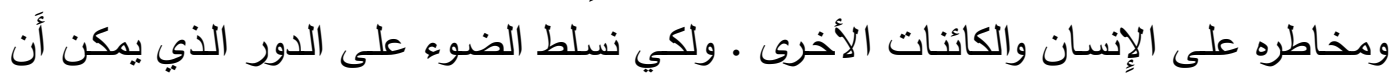

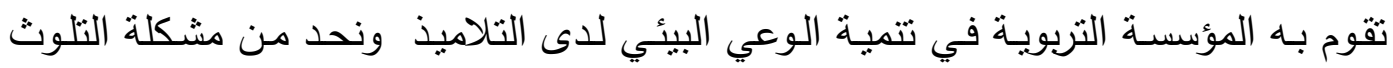
البيئي، يمكن بلورة المشكلة بالتساؤلات الآتية: 
1 - ما مدى اهتمام المؤسسة التربوية بقضايا البيئة ومشكلاتها

r - هل تساهم المؤسسة التربوية في اكتساب الطالب اتجاهات ايجابية نحو البيئة

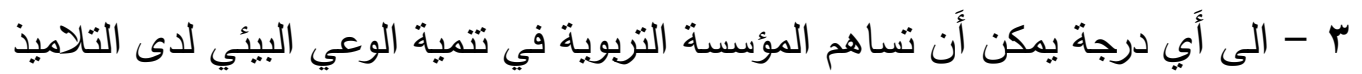

ثانياً: أَهمية الداسية آناجة

تكمن أَهمية الدراسة في تتناولها موضوعا على درجة كبيرة من الأَهية في حياة الناس وصحتهم إلا وهو الوعي البيئي الذي أَصبح ضرورة لا بد منها لمواجهة الاخطار المتزايدة

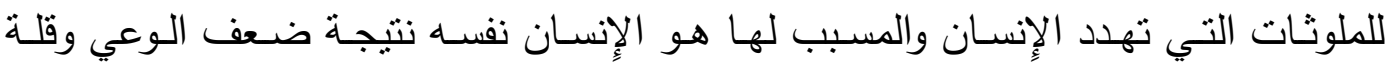
الإدرالك من جهة والتجاهل من قبل بعض الناس بخطورة هذه الملوثات من جهة اخرى.

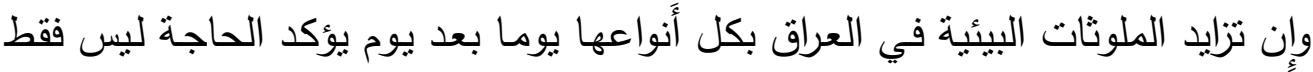

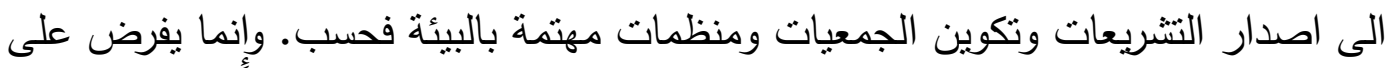
الدولـة دعم واهتمـام بكل المؤسسـات المعنيـة بالتتشـئة الاجتماعيـة لتبصـير وتوعيـة النـاس

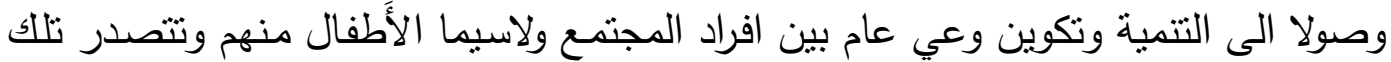

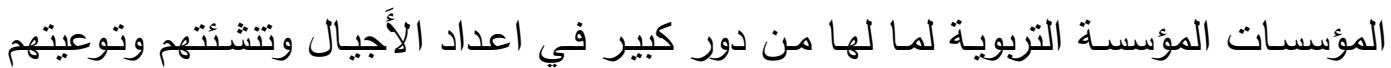

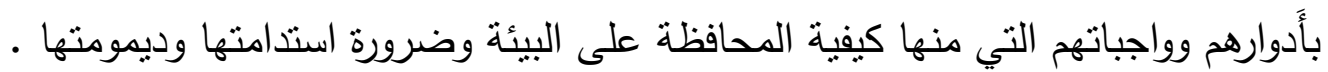

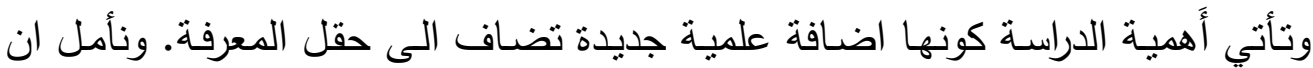
تساهم في الحد من الملوثات التي اصبحنا نراها في كل مكان عن طريق التوعية والتوجيه

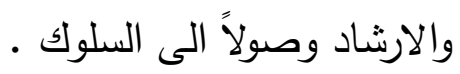

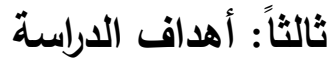
تهذف هذه الدراسة للتعرف على العلاقة بين المؤسسة التربوية وتتمية الوعي البيئي لدى التناميذ . . وكما موضح بالنقاط الآتية . 1 - التعريف بما هو المقصود بالوعي البيئي

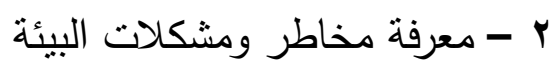

r - ما مدى دور المؤسسة التربوية بتمية الوعي البيئي لدى التلاميذ

رابعاً: تحديد المصطلحات العلمية للاراسة

يعد تحديد المصطلحات العلمية للاراسة وتعريفها خطوة مهمة في أَي دراسة ـ لتسهيل وتبسيط المفاهيم للمختصين وغير المختصين ومن أَهمها.

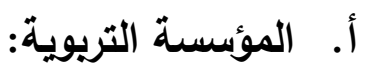

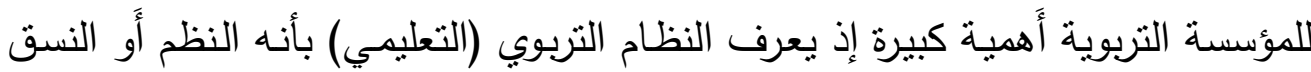
الاجتماعي الذي يتضمن الأدوار والمعايير الاجتماعية التي تعمل على نقل المعرفة من جيل

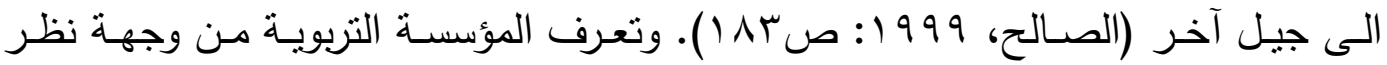


علماء التربيـة " أنّها ليست مكاناً فقط لتلقين معلومات وتكوين عادات من أَجل مستقبل

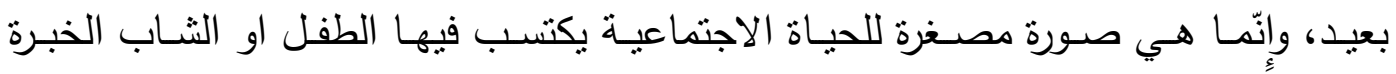

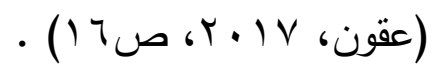
ثانياً: التنمية :

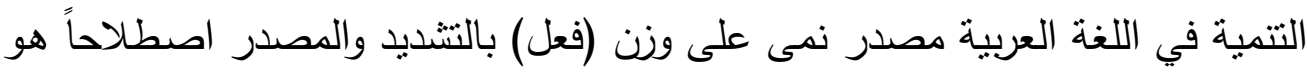

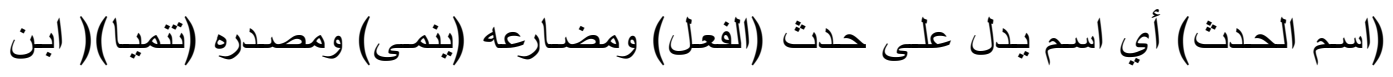

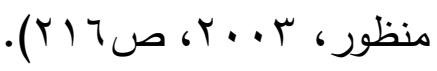

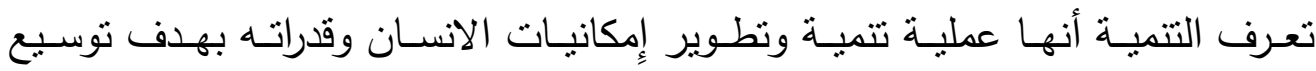

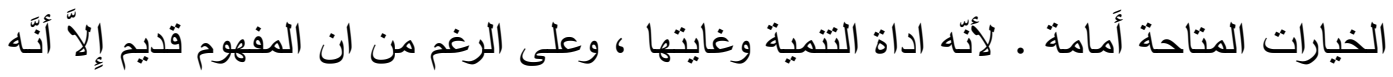

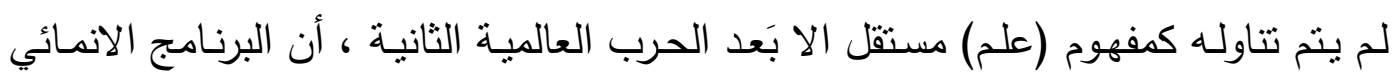

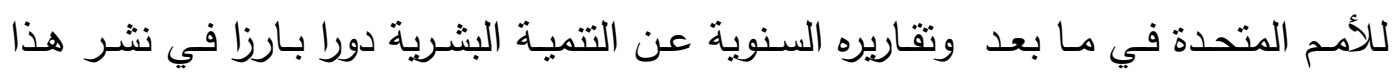

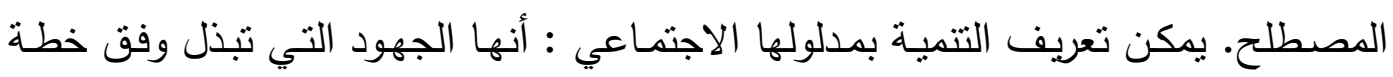

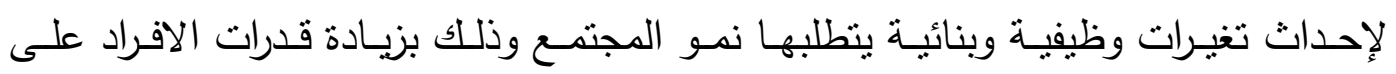

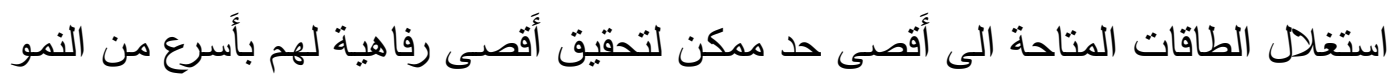

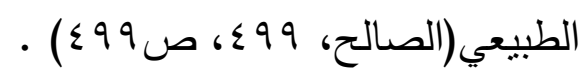

Environment : البياً البيئة أصلها في اللغة العربية من (بوأ) الذي أخذ منه الفعل الماضي (باء) وباء الى الى الئل

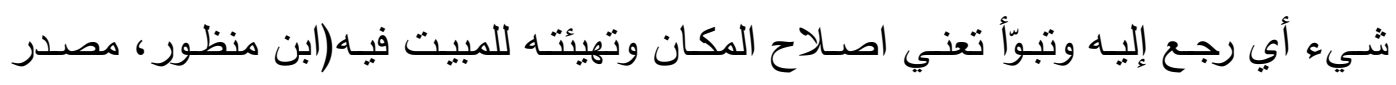

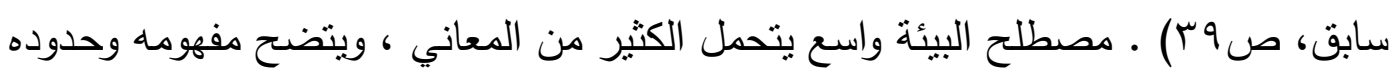

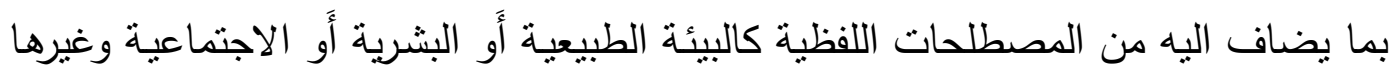

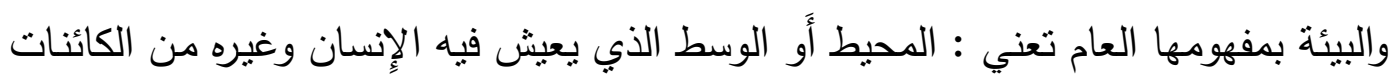

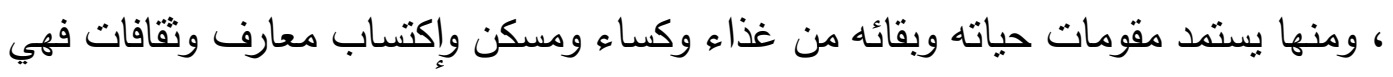

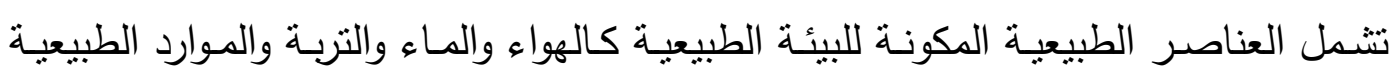

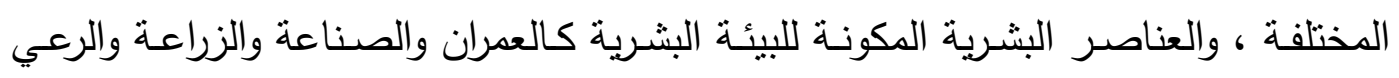

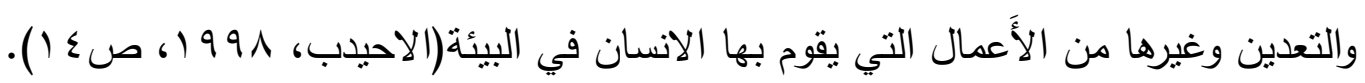

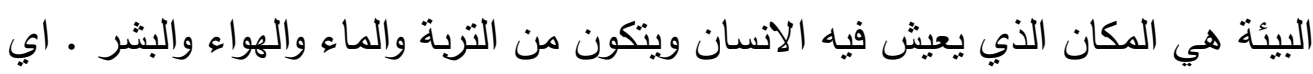

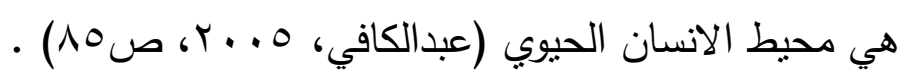

رابعاً : الوعي البيئي: Environmental Consciousness يعرف الوعي لغويا : وعي (وعاه) ـ أَي الثي الحديث (يعيه ) وعياً : (حفظه ) وفهمه

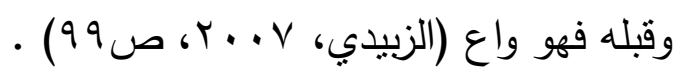


ويعرف اصطلاحاً : ادراك الفرد لنفسـه وللبيئة المحيطـة بـه، وهو على درجـات من الوضوح والتعقيد ، والوعي بهذا المعنى يتضمن إدراك الفرد لنفسه ولوظائفه العقلية والجسمية

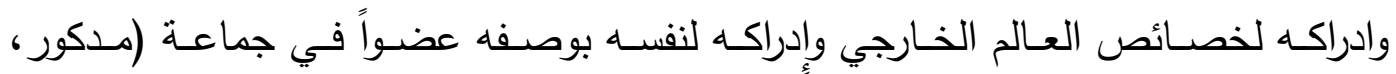

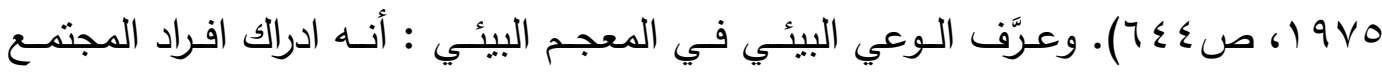
لأهمية المحافظة على البيئة وترشيد استخدام الموارد الطبيعية ومنع أَو الحد من تدهورها أَو

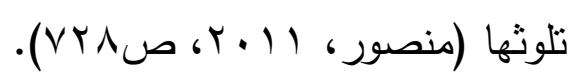

Environmental awareness : المبحث الثاني: الوعي البيئي ازدادت حاجـة افراد المجتمـع للخبرة والدرايـة الكافيتين لعناصـر وقضــايا البيئة وادرالك العلاقة التأثيرية المتبادلة لتجنب الوقوع في المزبد من الكوارث البيئية ، ويُعد الوعي البيئي والمعرفة من ابسط مستويات نكوين الاتجاهات والقيم لدى الافراد (أبو عميرة ، ع ا . ب ، ص. ( ) (Abu Amira, 2014, P10) ). والوعي البيئي هو عملية إعداد الإنسان للتفاعل الناجح مسع البيئة الطبيعيـة بما تحويـه من موارد متعددة وتتطلب هذه العملية العمل لتتمية جوانب معينة لدى المتعلم منها . ا ـ توضـيح المفـاهيم وتعميـق المبـادئ المطلوبـة في إِراك العلاقـة المتبادلـة بـين الإنسـان وبيئنه. r. تتمية القدرات والمهارات التي تمكن القرد من المساهمة في حل المشاكل التي تتعرض لها البيئة وما قد يهددها من أَخطار والمساهمة في تطوير ظروف البيئة . r. تكوين الاتجاهات والقيم التي تحكم سلوك الفرد إزاء البيئة وآثاره ميوله واهتماماته اتجاه

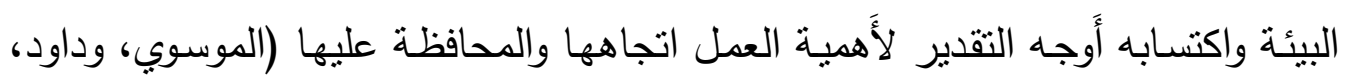

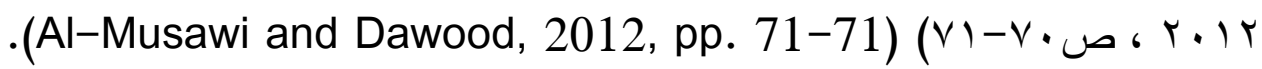
ا - أَهمية الوعي البيئي

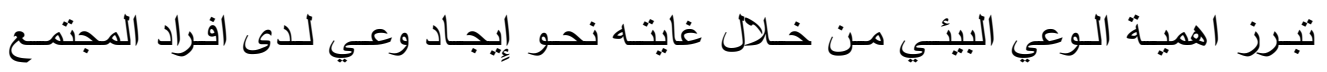

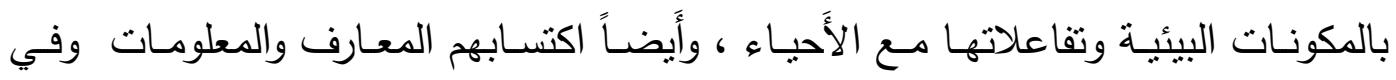
الَّنهاية تغير اتجاهاتهم السلوكية السلبية إتجاه البيئة وتعزبز الإيجابية منها ومشاركتهم في حل مشـكلات البيئة ومنـع اخطارهـا ، مـن خـلال تتميـة المهارات لمتابعـة القضـايا والإدارة البيئيـة المرتبطـة بـالنَّطور الاقتصـادي والاجتمـاعي من دون إلحـاق اضـرار بالبيئة لتحقيـق التتميـة المســدامة ، وإنَّ النهوض بـالوعي البيئي شـرط ضـروري في التصـدي للمشكلات والأخطار البيئية فيجعل الفرد يتصرف على نحو مسؤول تجاه البيئة ، ومن خلاله يتبنى

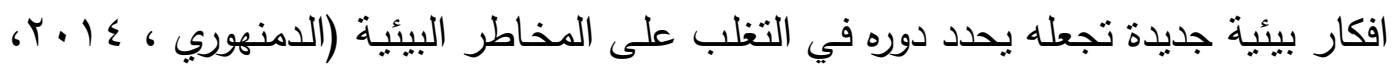
صal-Damanhoury, 2014, P259-260)(r . - (ro9) 


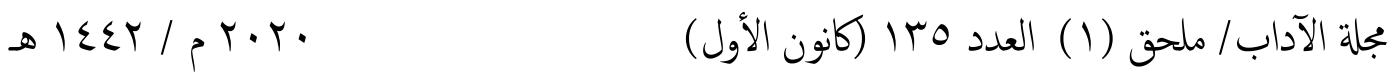

وتعددت الجوانب الايجابية للوعي البيئي في المحافظة على صحة البيئة وسلامتها ومن

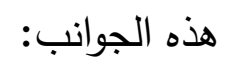

1- تزويد الفرد بـالفرص الكافيـة لإكسابه المعرفة والدهارة اتجـاه تحسين البيئة والمحافظـة

$$
\text { عليها. }
$$

r- يعمل الوعي البيئي بنطوير اخلاقيات بيئية بحيث تصبح البيئة وحالاتها هي الرقيب على الفرد عند تعامله مع البيئة .

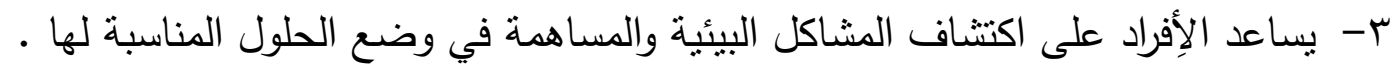

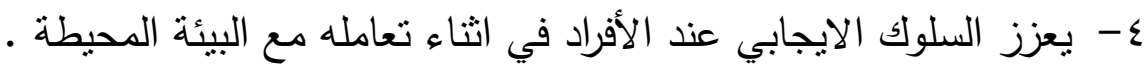

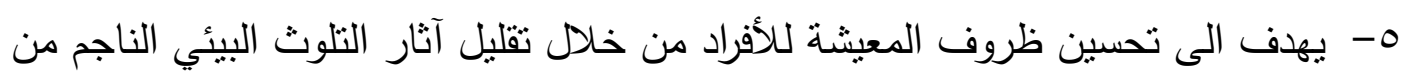
الأنشطة المختلفة .

צ- يعمل على الحد من تفاقم المشكلات البيئية وما يتبعها من أَضرار على النظام البيئي

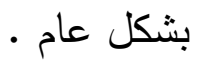

V- إِن غياب الوعي البيئي في اثثاء تعامل الأفَراد مع البيئة يقوي احتمالية حدوث توقعات

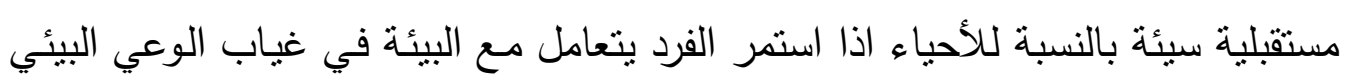

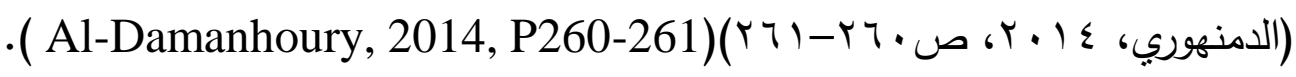

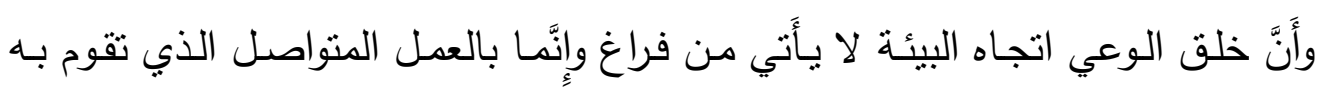

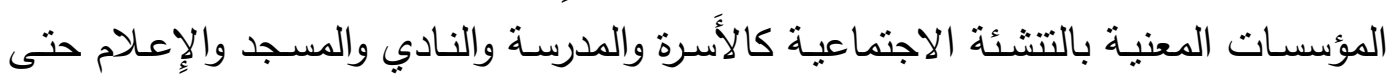
يتكون الإدراك الكافي بضرورة المحافظة على البيئة .

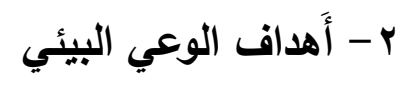

$$
\text { يسعى الوعي البيئي الى تحقيق عدد من الأَهداف منها : الهئ }
$$

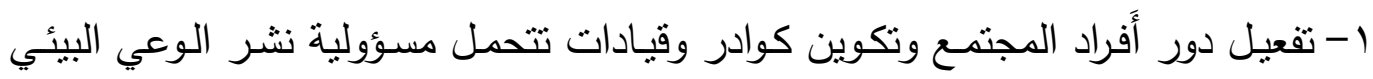

$$
\text { بالتواصل المباشر بالمدارس والجامعات. }
$$

ץ- الارتقاء بالبيئة وحمايتها وصيانة مواردها المتعددة والعمل على تثـخيص مشكلاتها

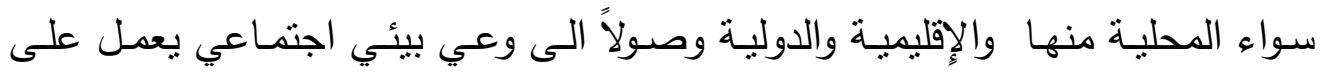

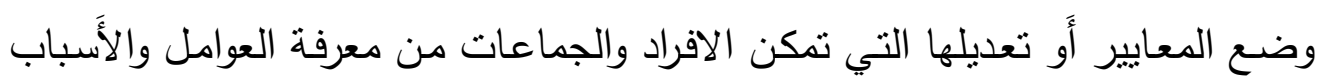

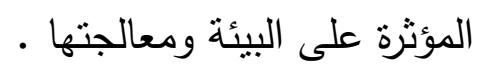

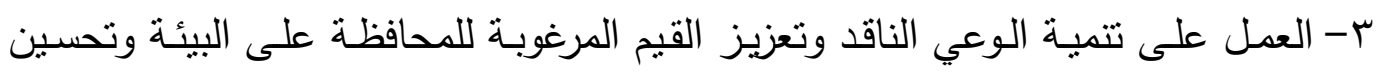

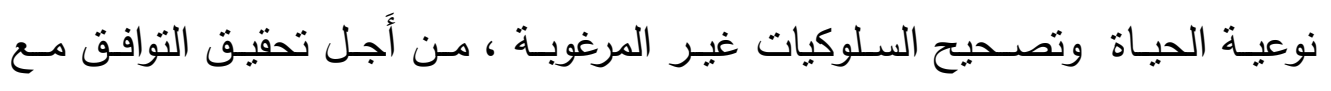

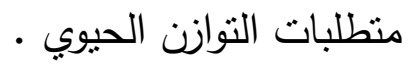




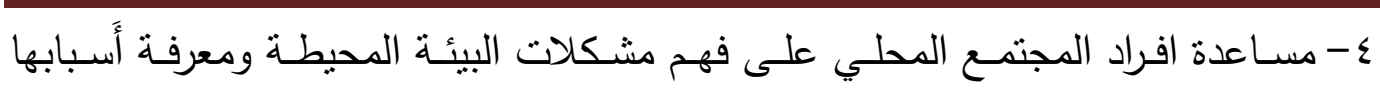
وتجنبها وتتجيعهم للمشاركة في إيجاد حلول مناسبة لها .

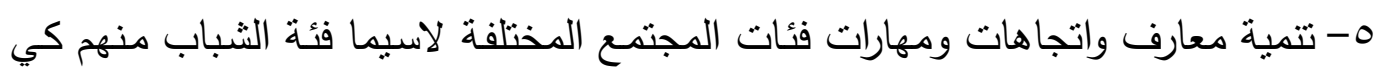

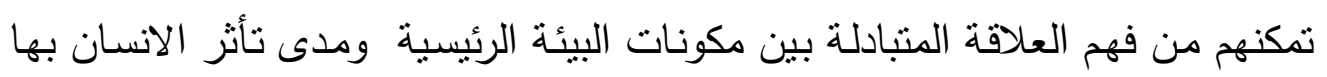

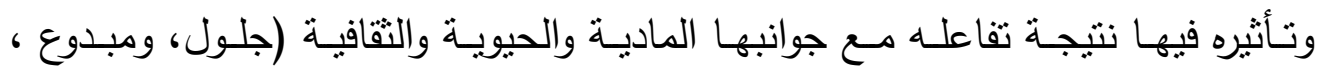
.(Jalloul and Mabdue, 2017, P57-58) (ON-OV ص r. IV فمن الملاحظ أَنَّ مجمل الأَهداف التي يسعى لها الوعي البيأي هي المعرفة والإدراك

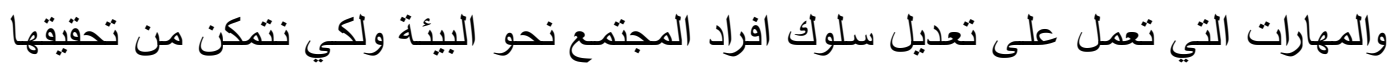

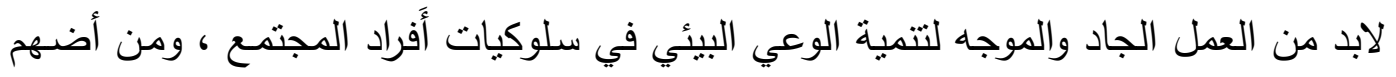

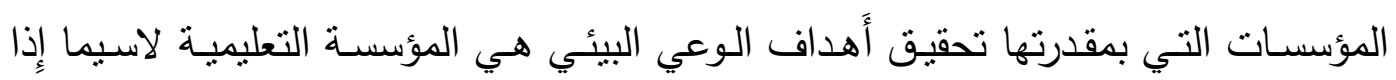

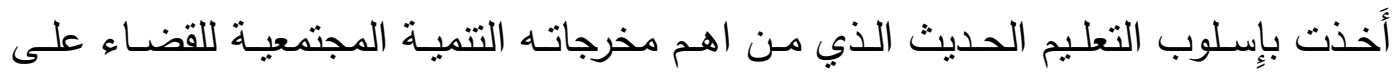
مشكلات المجتمع ومنها تكوين اتجاهات صديقة للبيئة . r- الوعي البيئي ضرورة حتمية لمواجهة الملوثات البيئية

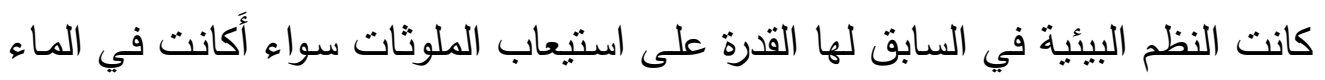

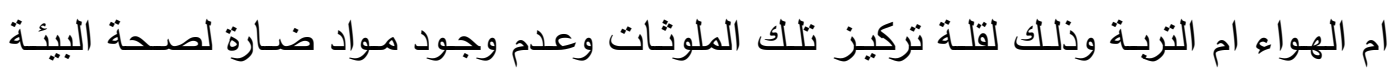

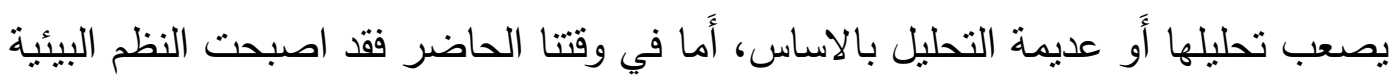

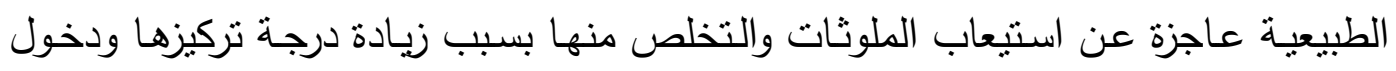

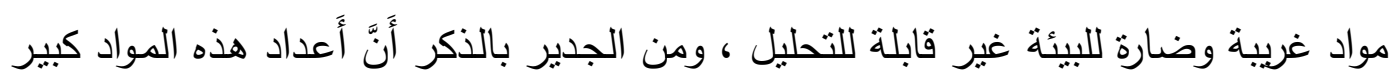

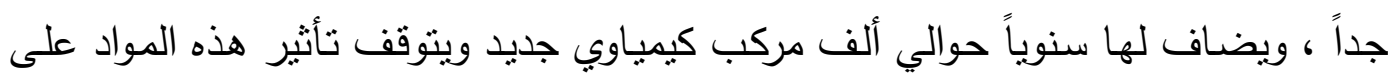

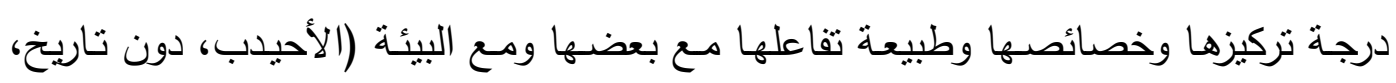
ص (r) (Ahaidib, without date, P21)

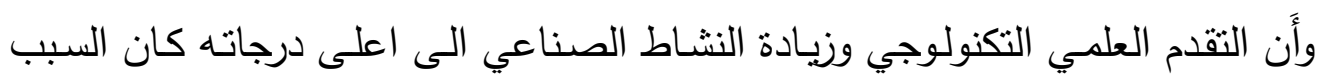

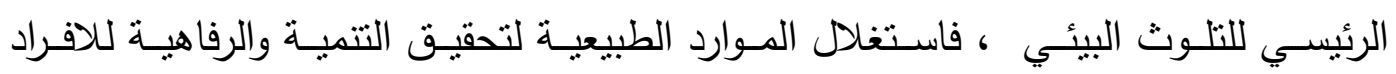

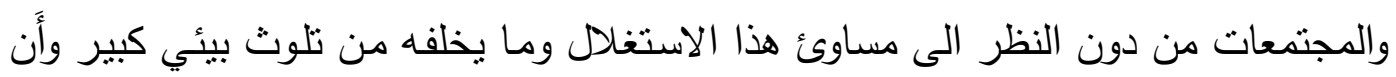

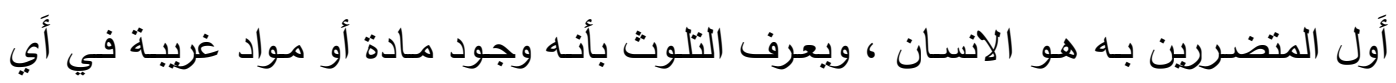

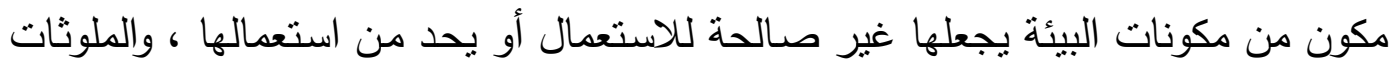

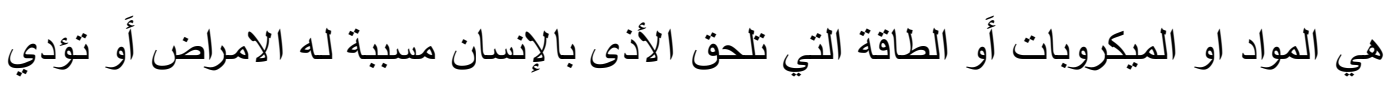
به الى الموت (الأحيدب، دون تاريخ، ص آب) (Ahaidib, without date, P21). 
والتلوث البئي لا يعرف الغني والفقير او الملك والمملوك فالكل مستهدفة لذا يستوجب من الجميـع العمـل مـن اجل تحقيـق الـوعي البئِي الذي يجعـل مـن الجميـع أَدوات مراقبـة ومتابعة لسلوكياتتا اتجاه البيئة .ويقسم التلوث البيئي الى:

$$
\text { ا } 1
$$

يُعدُّ تلوث الهواء من اخطر انواع التلوث ، وان اخطاره عابرة للحدود الادارية والسياسية ومن أَهم مصسادره هي الدخان والغازات التي تخلفها المولدات الكهربائية والمصـانع وعوادم السيارات كما تعد الغازات المنبعثة من الفضالات والقمامة المرمية في بعض الأَماكن والاتربة

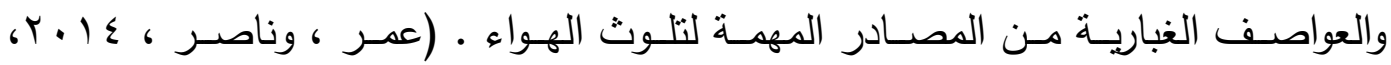

(Omar and Nasser, 2014, P215) (Y) (Y) وتتسع دائرة مخاطر تلوث الهواء لتشمل كل الكائنات الحية وايضاً المنشآت والمنتجات الصناعية والمناخ وطبقة الاوزون ويتأثز الانسان بالتلوث الهوائي مباشراً ، بحيث يسبب لله الكثير من الامراض التي بداً بعاني منها الانسان في عصرنا الحالي ، كأمراض الجهاز

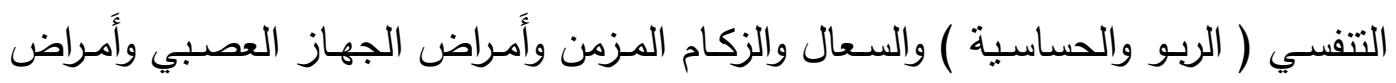

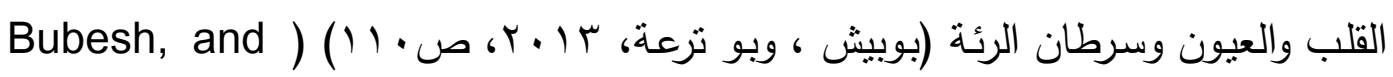
.(Bu teriea, 2013, P110 وهنا يأني دور الدولة بضـرورة إبعاد المصـانع عن المناطق السكنية وأَن تكون عكس اتجاه مصدر الرياح حتى لا تتقل الغازات السامة الى وسط المدن ، كما يجب اعادة العمل

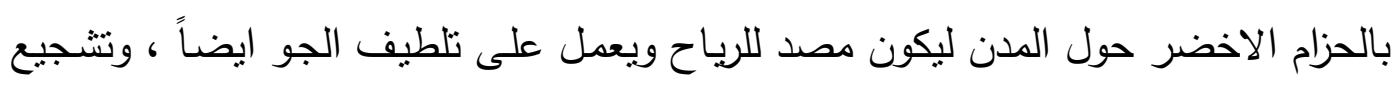
المواطنين على زراعـة الاشتجار في المنـازل والثـوارع والمدارس والمحافظـة عليها وتكوين وعي بيئي بكل الوسائل التعليمية والاعلامية لخطورة تلوث الهواء وطرق الوقاية . r - بلوث المياه

تُعد المياه من اهم الموارد الطبيعية ، وقد بينت الدراسات والبحوث التي درست الموارد المائية أَن المياه وما يتعلق بها من انشطة سنصبح هم البشرية في السنوات القادمة ، لأَََّّ المياه العذبة لا تتجاوز نسبتها ب\% من نسبة تواجد المباه على سطح الارض ، وأَن صحة الانسان ورفاهيته والأمن الغذائي والتتمية الصناعية والنظم الايكلوجية معرضة للخطر اذا لم

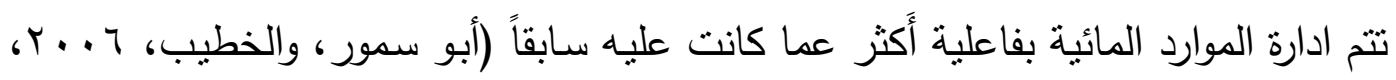
ص (Abu Sammour, and Al-Khatib, 2006, P346) (1) وأَن تلوث المياه بالمواد العضوية والمواد الكيميائية والبكتربا الضسارة يؤدي الى انتقالها الى الإنسان عن طربق الجلد أو الجروح أو الفم عن طربق الثرب أَو السباحة في المياه الملوثة ، ومن الأمراض التي يسببها تلوث المياه التيفوئيد والنزلات المعدية والإسهال والقيء 
والكوليرا والتهابـات الكبد والجهاز العصبي وغيرهـا التي سبيها مخلفـات الإنسـان بصـورة

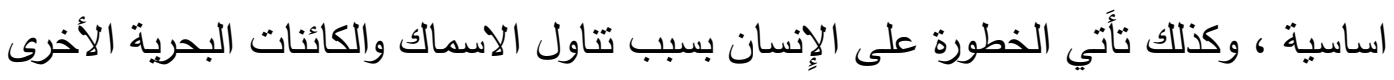

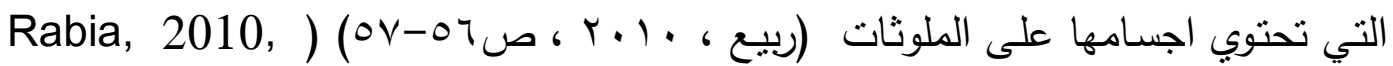

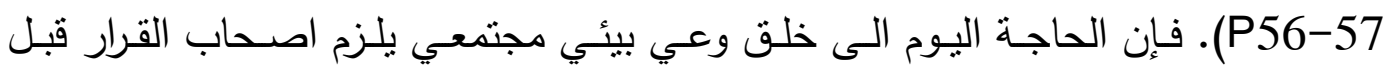

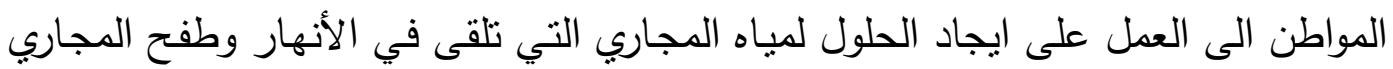
التي تغرق المناطق السكنية لاسيما عند تساقط الامطار وما تخلفه من آثار خطيرة يستدعي لئاه تكوين وعي بيئي شعبي ضاغط للقضاء على هذا التلوث .

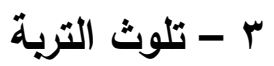

يجري التغير الضـار في التركيب الطبيعي للتربـة بتأثثر العوامل الفيزيائية والكيميائية

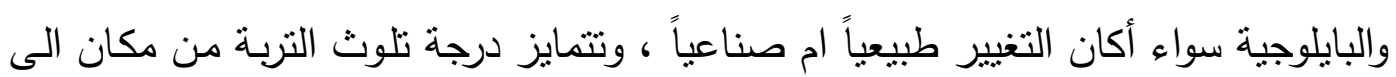

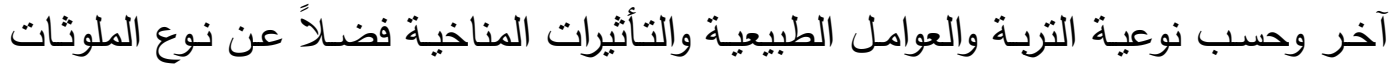

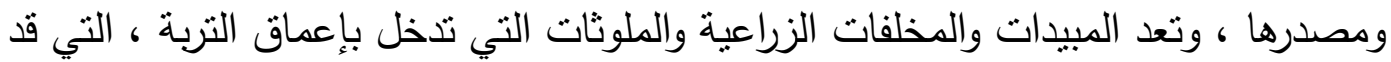
تجد لها طريقاً الى سطح الأَرض من خلال الخاصية الثعرية والنقل بالمياه الجوفية من أَهم

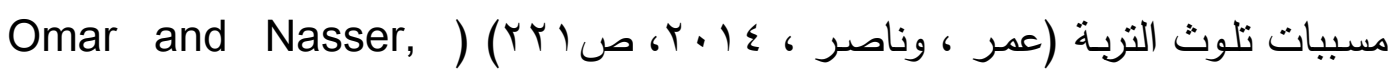
.(2014, P221 ؛ - 2 - التلوث الاشعاعي

يسبب التلوث الاشعاعي أَمراضاً كثيرة كتساقط الثعر وظهور النسلخات الجلدية على الثى الأَفراد المتعرضين للنشـاط الاثـعاعي الى تلف نخاع العظام وتعطيل توليد كريات الدام البيضاء والحمراء وضعف مناعة الجسم نتيجة الامراض الداخلية مثل التهاب الكبد والكلى الكى

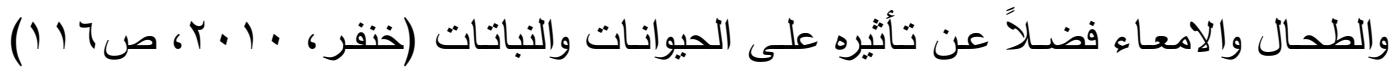
(Khanfar, 2010, P116)

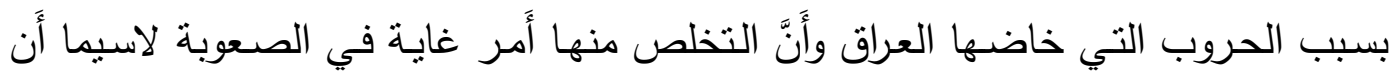

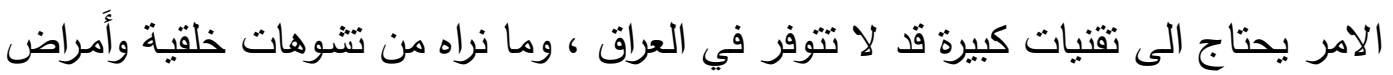

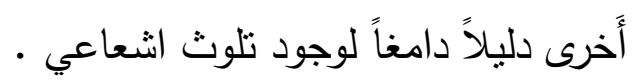

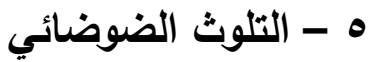

هو كل الاصـوات غير المرغوبـة التي تحدث أضراراً جسيمةً للأفَراد المعرضين لها

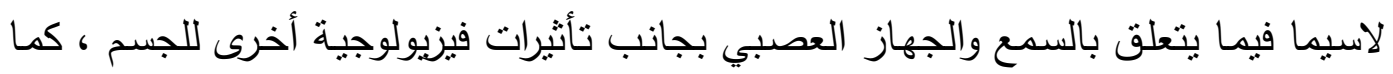

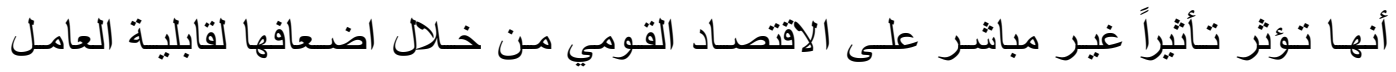
الانتاجية اليومية ، فيؤدي ارتفاع شدة الصوت عن المعدل الطبيعي الى آثار نفسية خطيرة

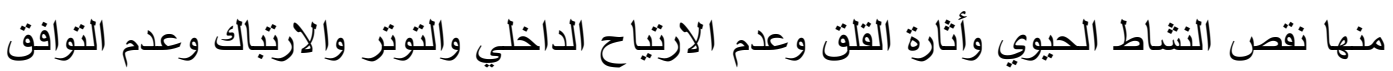




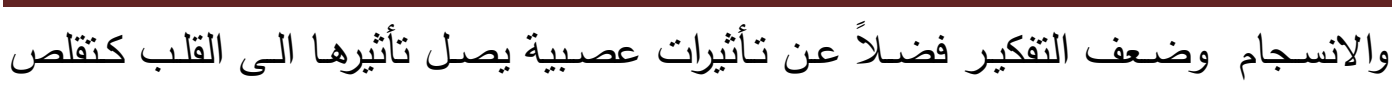

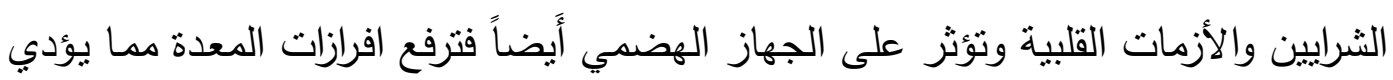

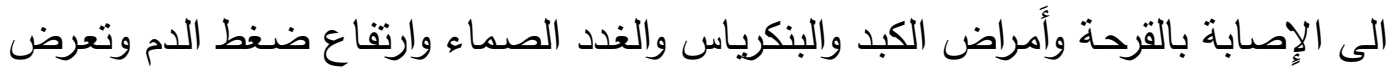

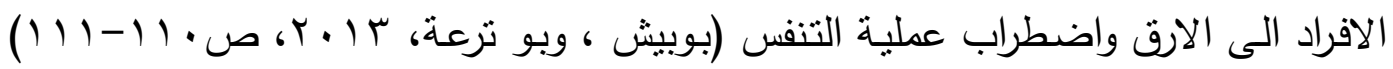
.(Bubesh, and Bu teriea, 2013, P110-111) ومن أهم مصادر الضوضساء أَصوات المكائن والسيارات وأَصِوات القطارات والطائرات

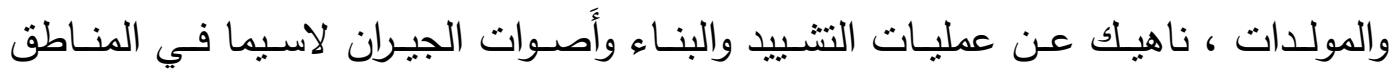
المزدحمة بالسكان ولصغر المساحات السكنية بالوقت الحاضر مسببة آثاراً صحية للأفَراد

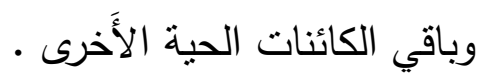

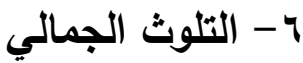

يتمثل التلوث الجمالي البصري في عناصر البيئة المحيطة في مدننا المعاصرة بحيث

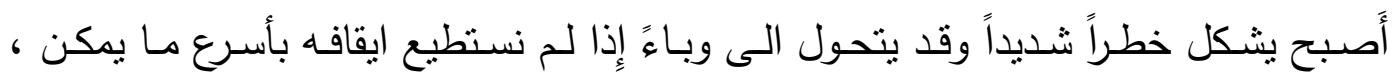
فانعدام مظاهر الجمال في مدننا سوف يؤدي بمرور الوقت الى فساد الذوق واعتياد القبيح

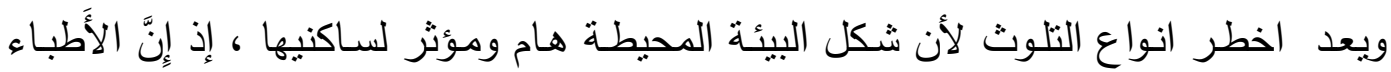

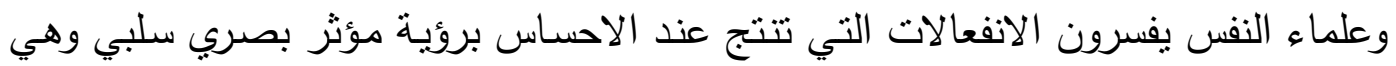

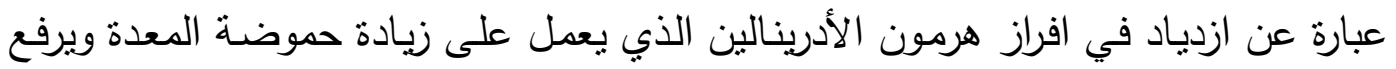

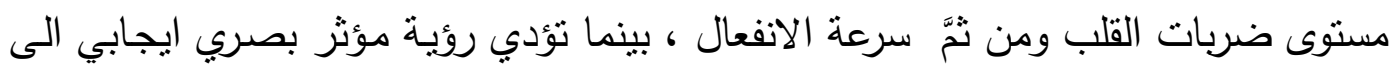

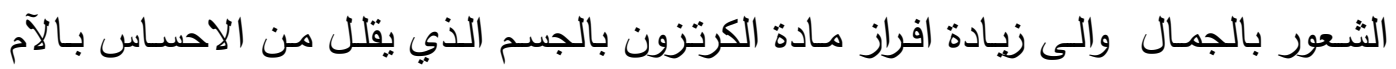

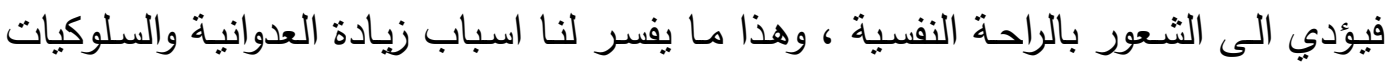

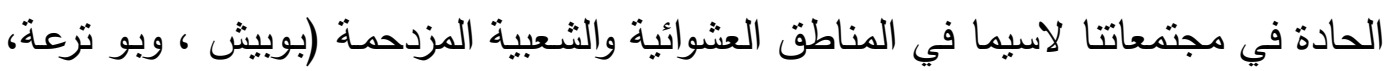

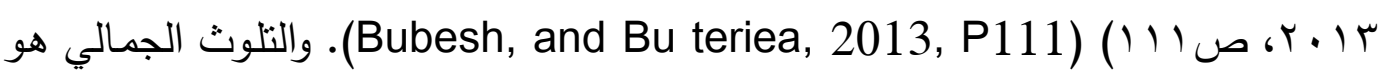
رؤية المشاهد المشوهة وغير المتجانسة المضرة بعين المشاهد لها ـ

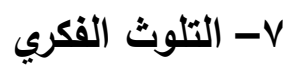

ويعني به حالات التغير بالنظم الاجتماعية أَو البنية الاجتماعية للمجتمع التي اعتاد

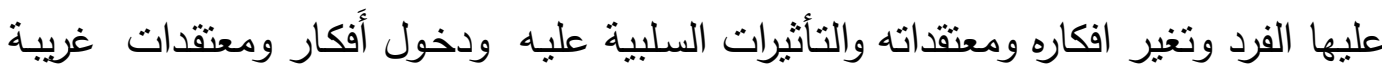

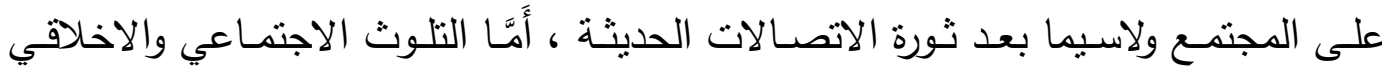

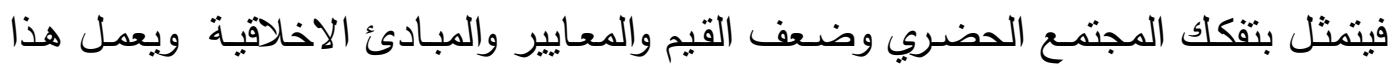
التفكك على ضعف عوامل الضبط الاجتماعي فتضعف سلطة المجتمع على أَفراده فيفعل وضعل

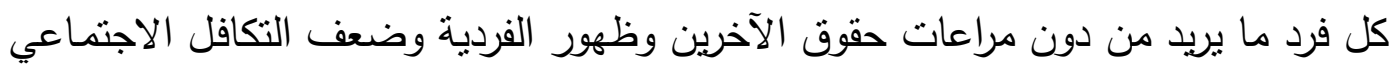




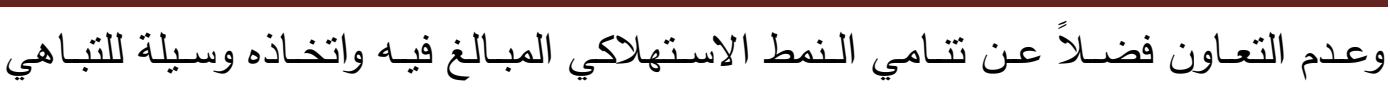

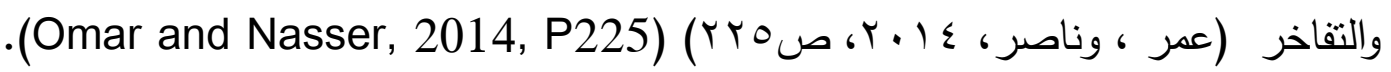

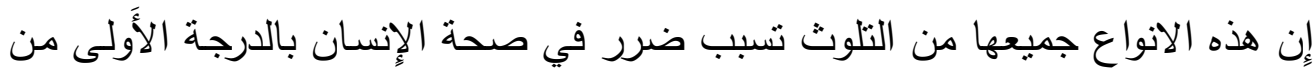
جهة والمسبب لها هو الإِنسان نفسه من جهة أَخرى ، نتيجة طدعه لتحقيق أَعلى الارباح

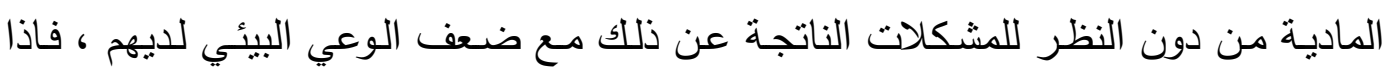

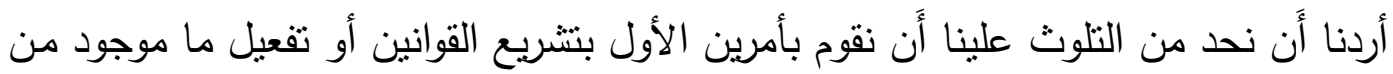

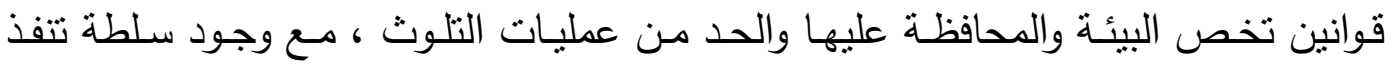

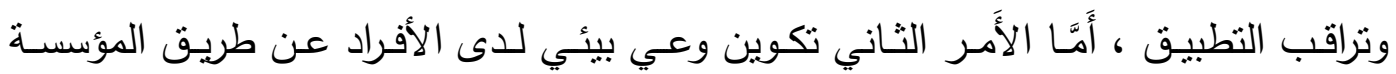

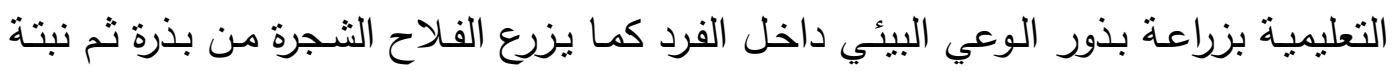

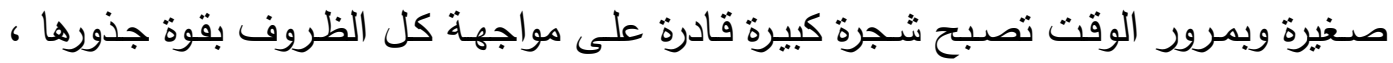
فالفرد اذا ما تمت تتشئته وتوعيته منذ الصغر على حب البيئة وتكوين المهارات بكيفية المحافظة عليها سوف تصبح بمرور الوقت عادة طبيعية من ضمن سلوكيات حياته اليومية

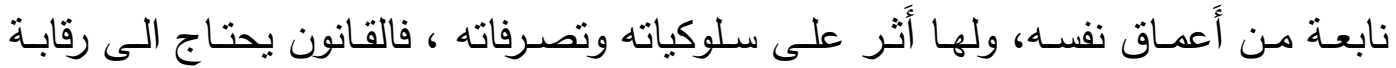

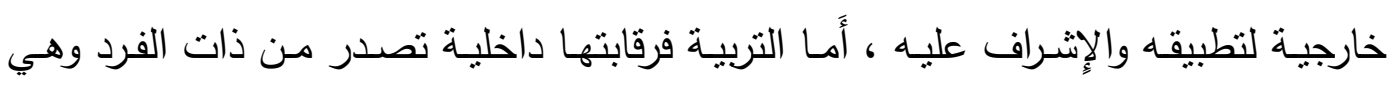

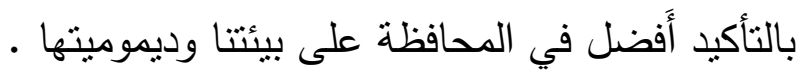
المبحث الثالث: التنمية والوعي البيئي:

\section{Environmental awareness and development}

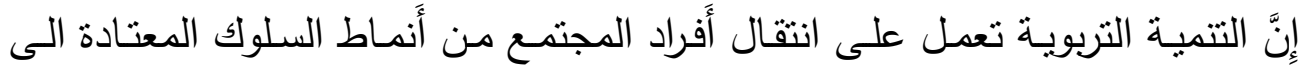

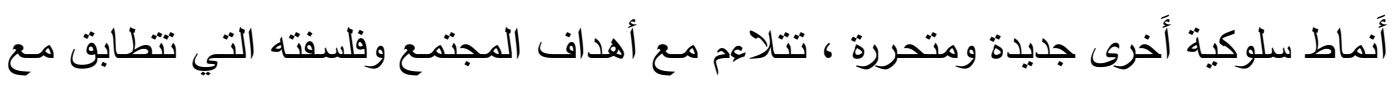
متطلبات خطة التتمية الثاملة ، كما تعمل التربية على تهيئة واعداد القوى العاملة المدربة

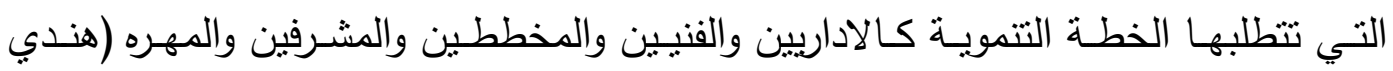

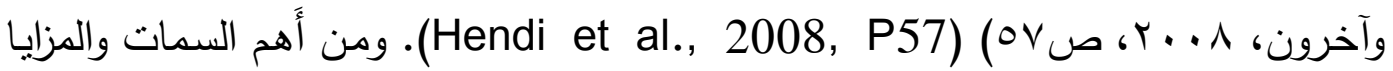

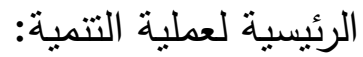

1- إِنَّ التتميـة عملية ذاتيـة وأَصلية أَي أَنَّ كُلَّ بذورها ومقوماتها الأَصلية موجودة داخل

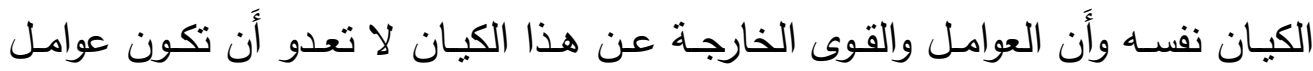

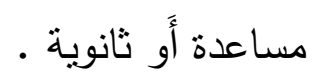

r- التتمية عملية ديناميكية مستمرة أي إنَّها ليست حالة ثابتة أَو جامدة. r- متعددة الطرق والاتجاهات وليست ذات طريق واحد ولها استراتيجية الاختيار من بين التهاته البدائل في اتجاهات التنمية لتحقيق الثمولية ـ النيات 


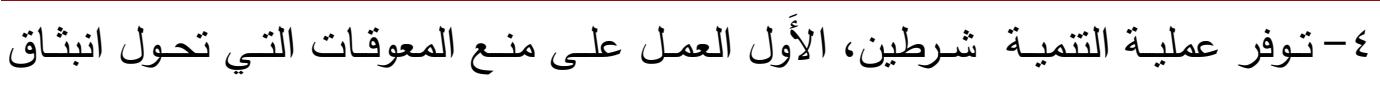

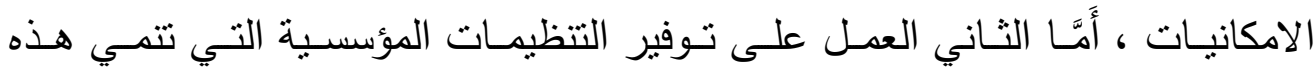

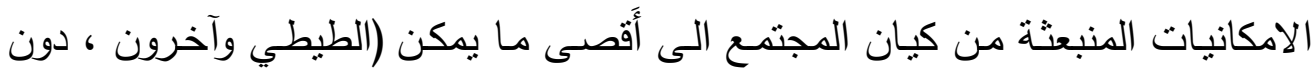

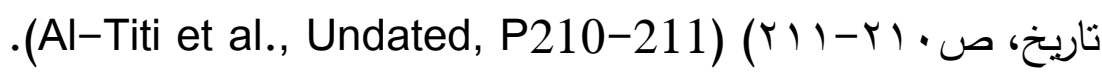

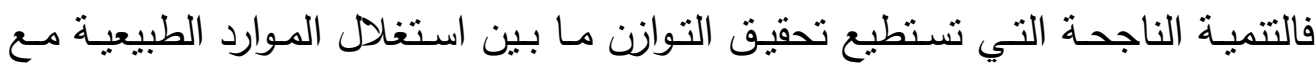
الحفاظ على حصة الأَجيال القادمة من جهة والمحافظة على البيئة من التلوث من جهة

\section{الوعي البيئي من أجل التنمية:}

أصبحت البيئة اليوم جزءاً لا يتجزأ مـن التتميـة بمعناهـا الثـامل بل وأحد منطلقاتها

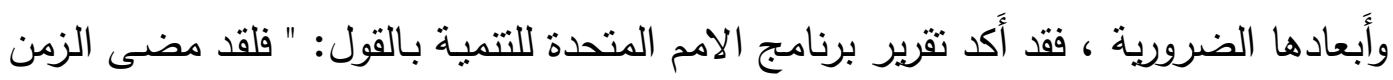

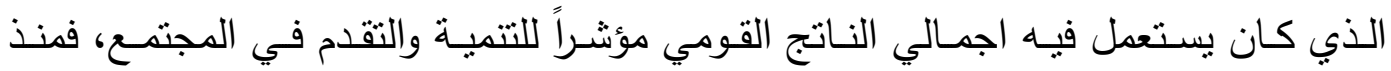

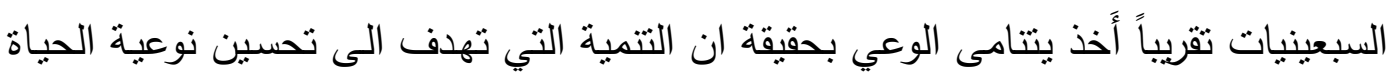

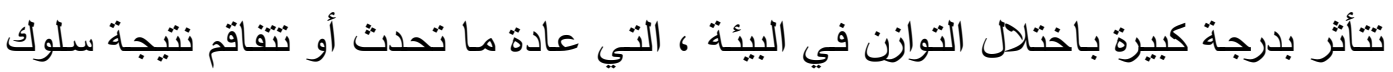

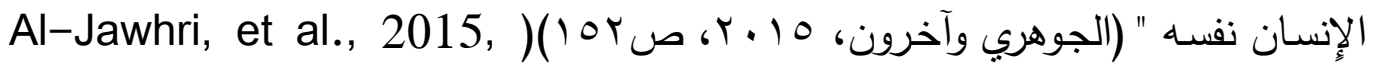

وأَن من أَصعب المهام التي نواجه الدول هي مهمة النهوض التتموي ونجاح خططه وأَن

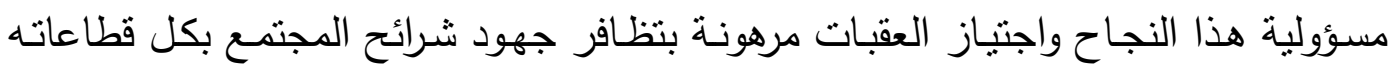

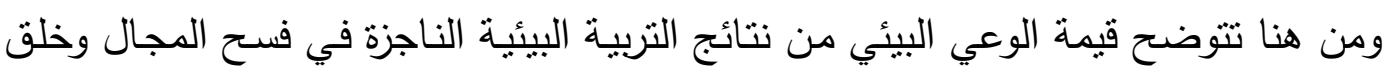

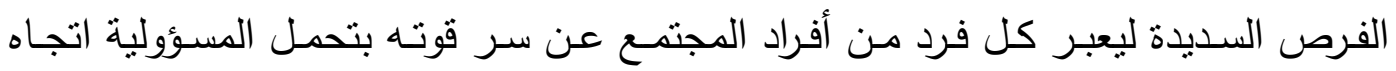

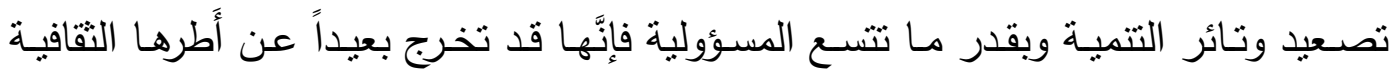

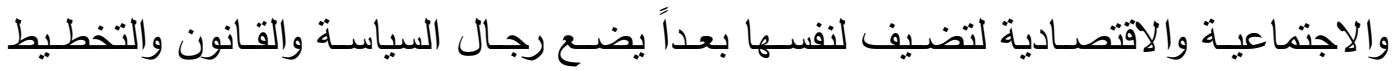
والتشريع وباقي العلماء والمفكرين والمربين في خضم المسؤولية للعمل على تكامل البيئة

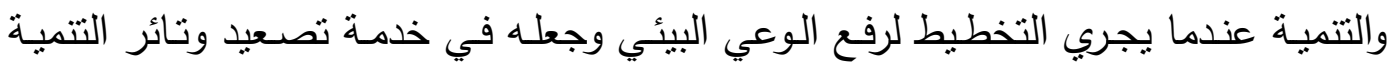

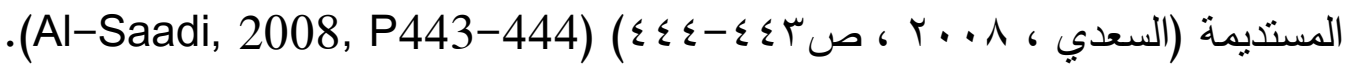

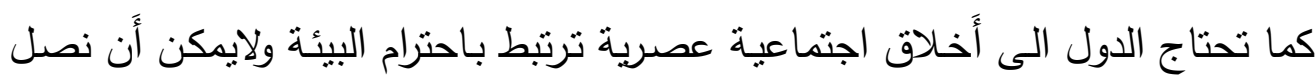

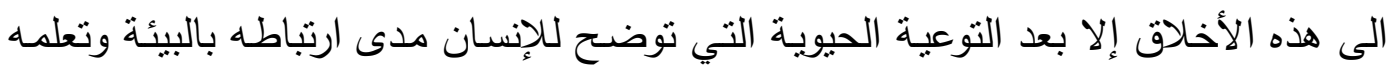

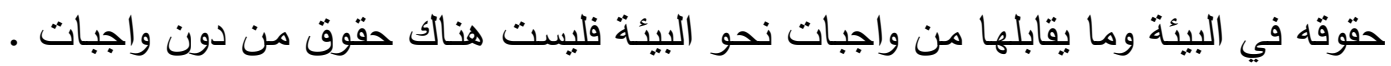

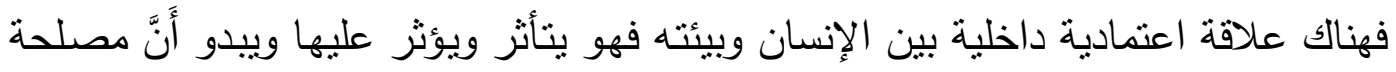
الإِنسان تكمن في وجوده ضمن بيئة سليمة حتى يستمر في حياته صحية سليمة (كاتوت،

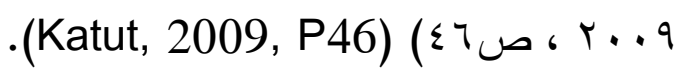


ولتحقيق نوعية حياة أَفضل للسكان ينبغي التركيز على العلاقات في نشاطات السكان

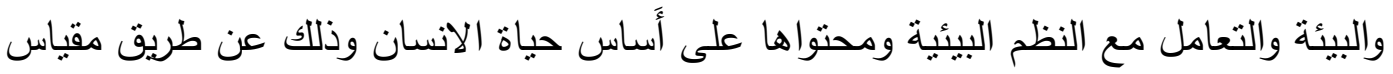

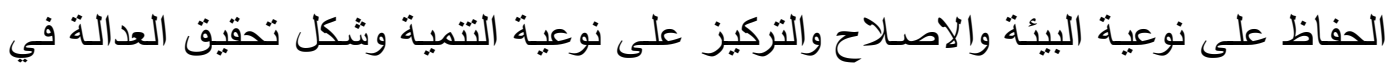

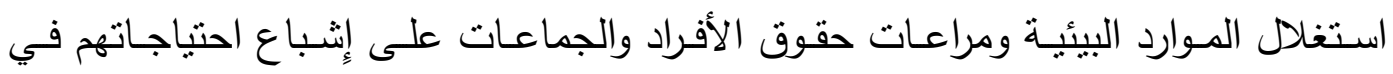

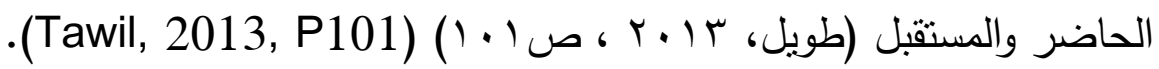

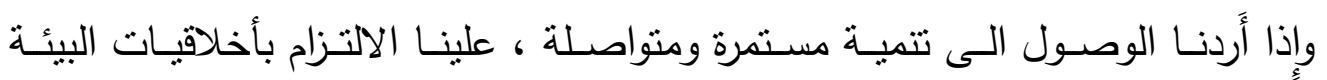

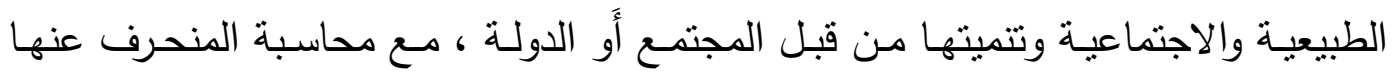

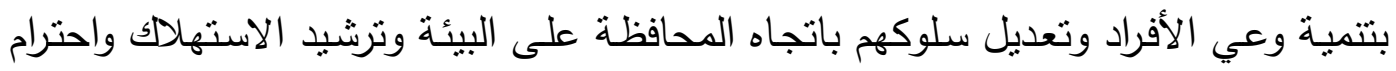

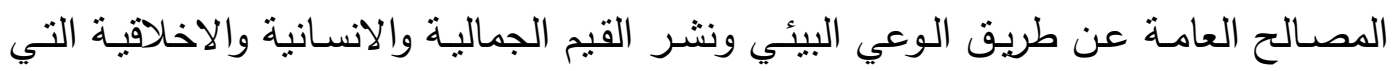
يمكن تعلمها من المدارس وتكوين مهارات التواصل والتفكير الناقد وكذلك مهارات تطبيق

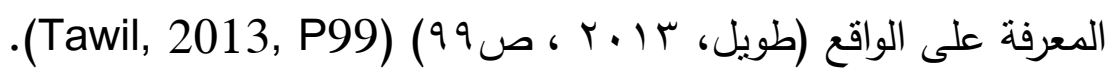

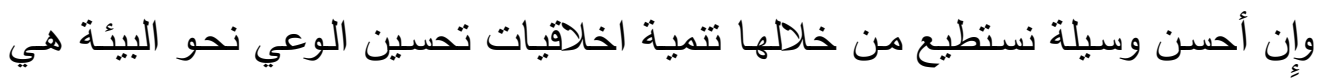

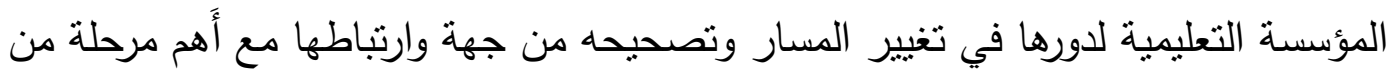
مراحل نمو الانسان هم الاطفال والمراهقون الذين هم قادة المستقبل وعليهم مسؤولية التغيير

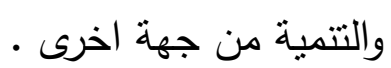

فالعنصر التزبوي ضروري لنتمية سلوك الأفَراد نحو احترام القوانين والتشريعات فضلاً

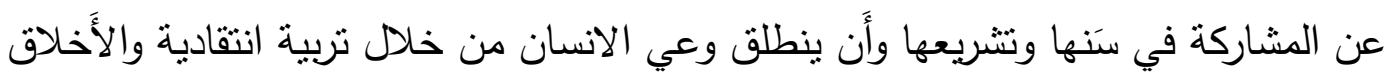

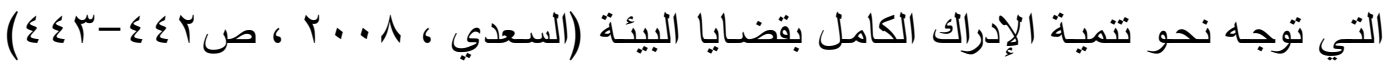
(Al-Saadi, 2008, P442-443) منهجية العلاقة بين البيئة والتنمية: هناك علاقة استراتيجية متبادلة بين التتمية والبيئة فتتأثر كل منهما بالأخرى من خلال: 1- تحديد مصادر التلوث الرئيسية ومناقتشة كل مصدر منها . r- متابعة هيكلية المؤسسات المعنية بحماية البيئة وفحص مكوناتها والعمل على تحديثها

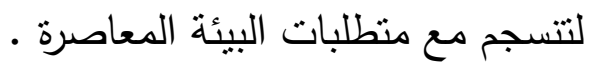

ب- يجب الربط بين البيئة والتتمية وأَنَّ الموارد الطبيعية هي حق وملك الاجيال والاستثمار ينبغي أَن يكون قائماً على قاعدة حماية الدورة الطبيعية.

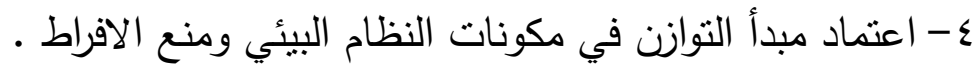

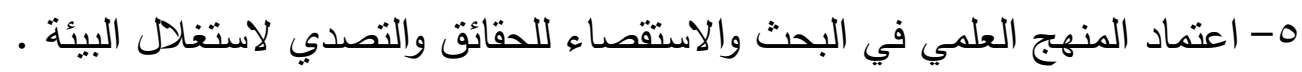
1- اتخاذ منهجية التربية والتاهيل من أَجل أثافة بيئية. 
V- تحويـل موضـوعات البيئـة الـى موضـوعات شـعبية مـن خـلال تثـكيل الجمعيـات والمنظمات.

^- التداخل ما بين المشاريع الاقتصادية والاجتماعية يقضي رؤية وممارسة دقيقة تعمل

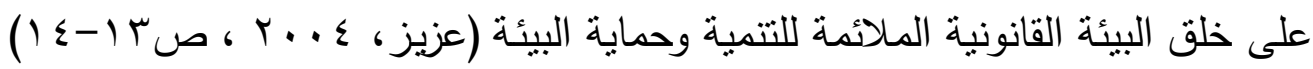
.(Eaziz, 2004, P13-14)

\section{العوامل المؤثرة على تنمية الوعي البيئي}

هناك عوامل مؤثرة في عملية التتمية من أَجل البيئة وسلامتها ومن هذه البئية العوامل هي: أولاً: الانفجار السكاني إن التزايد السكاني المنسارع في العالم يعمل على زيادة الضغط على الموارد من أَجل توفير احتباجات السكان ، فتتجه دول العالم نحو زيادة الانتاج الزراعي الذي يتطلب زيادة الناديا

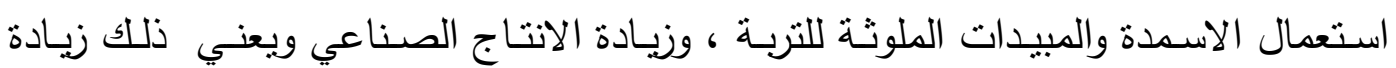

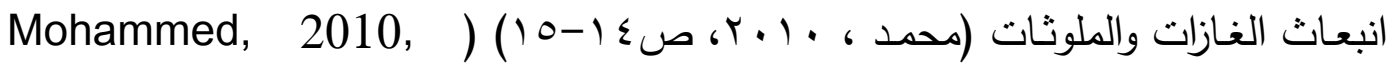

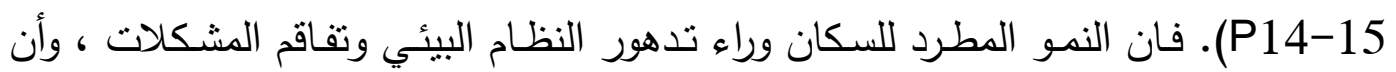
نقص الغذاء وقلة المياه العذبة وارتفاع نسبة الملوثات من أهم أسبابها الزيادة السكانية وأن

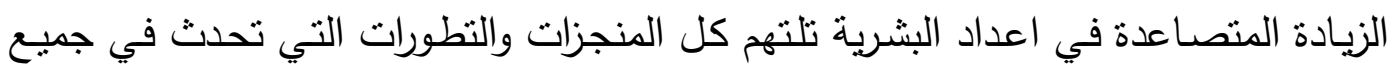

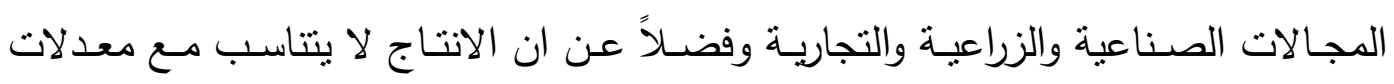

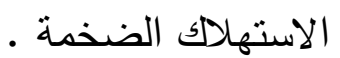

والنمو السكاني المتزايد والتطور التتموي غير المستدام للقطاعات المختلفة وقلة استعمال

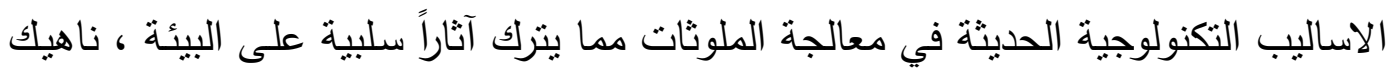

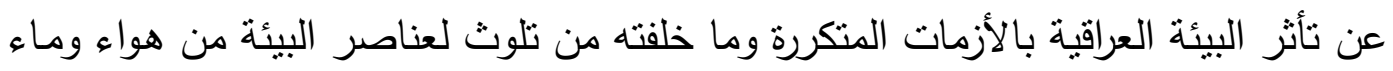

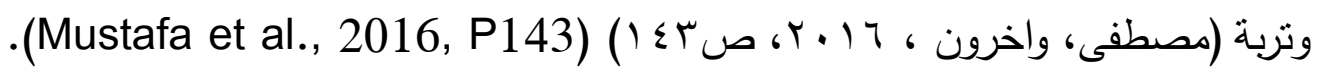

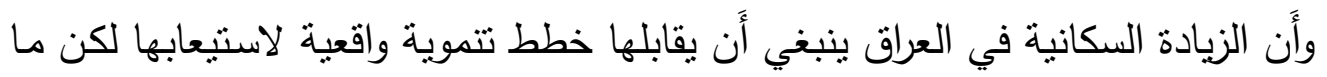

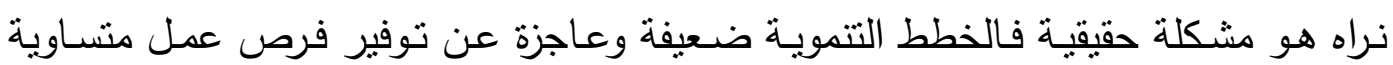

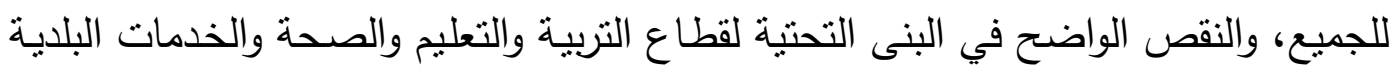
وانتشار العشوائيات لاستيعاب العداد المتزايدة في السكان مما خلق واقعاً بيئياً متخلفاً بكل النكل

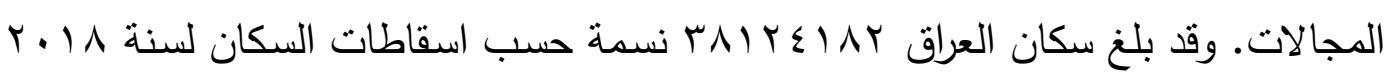

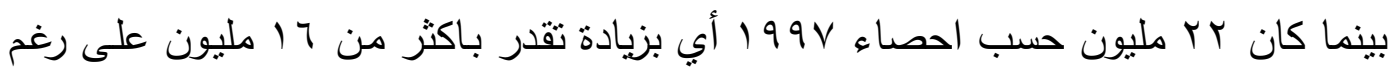

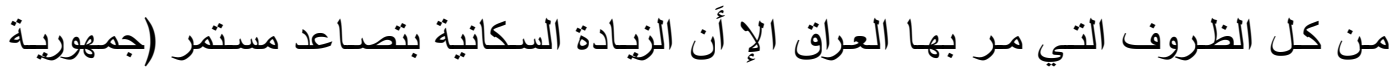

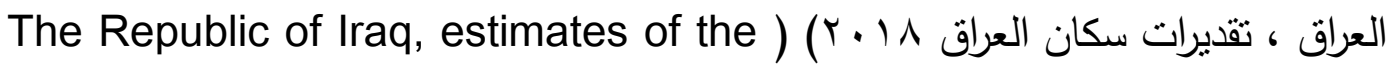
.(population of Iraq 2018 
ويحول التضخم السكاني جميع واردات الدولة لسد النقص الحاصل في الغذاء ، بما فيها الاموال المخصصة للتنمية مما يجعلها في دائرة التخلف والركود مع تتامي المشكلات

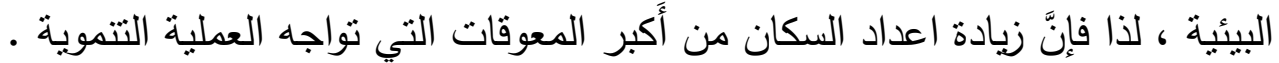
ثانياً: الفقر

الانسـان كائن بيئي من المفروض أن تتوفر لـه الظروف المناسبة للعبش في بيئة إِنسانية ، فلا يمكن النظر الى البيئة دون رؤية انسانها، كما أَنه لا يمكن النظر الى لئى الإنسان

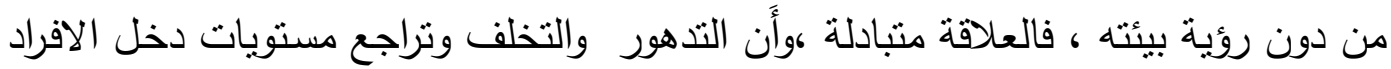
والمجتمعات يفضي الى مزيد من التدهور في البيئة ومن أجل حماية مواردنا الطبيعية يتطلب

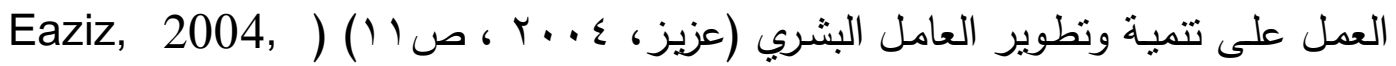

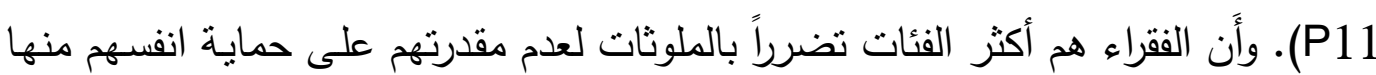
من جهة وأكثر الفئات الذين يعرضون البيئة الى الخطر من جهة اخرى والفقبر كل همهـ

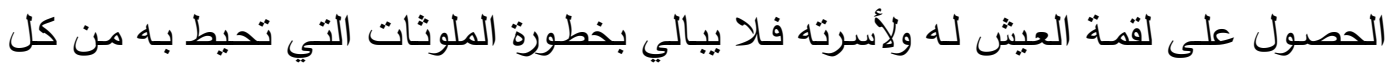

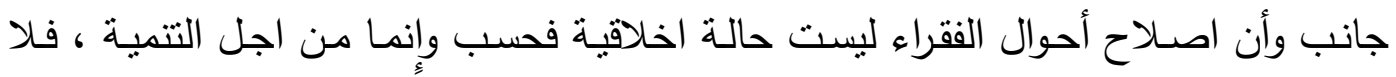

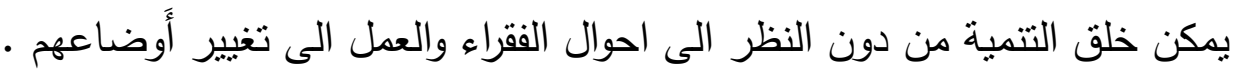
ولقد ورثت الدولة العراقية عبء الفقر التراكمي وما استجد معهه من عوامل كالبطالة

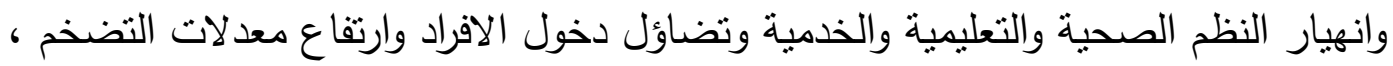

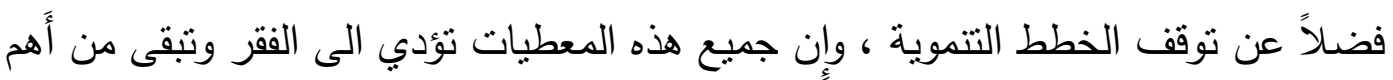

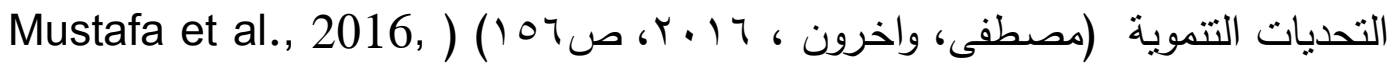

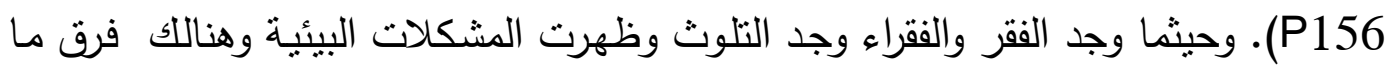

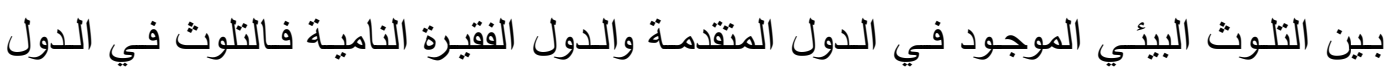
المنقدمة نتيجة الثورة الصناعية والتقدم العلمي ، أَمَّا في الدول النامية فنتيجة عدم استغلادل

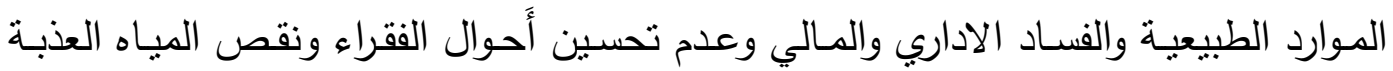
وطفح المجاري، من أَسباب ظهور التلوث ، فالفقر هو السد المنيع الذي يقف بوجه التتمية .

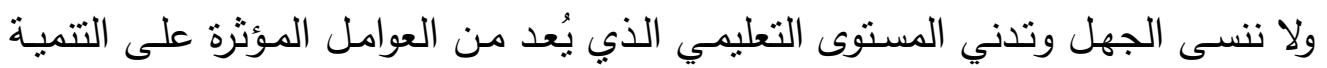

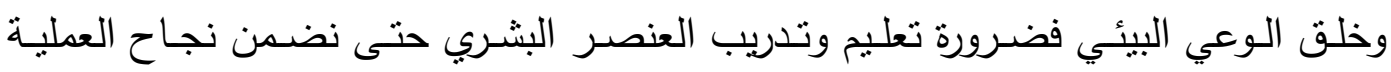

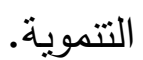

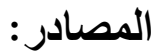

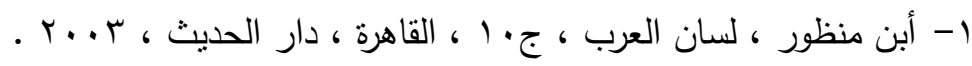

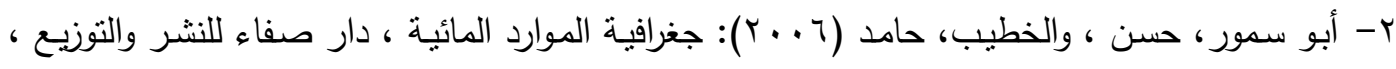

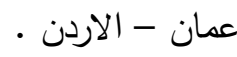




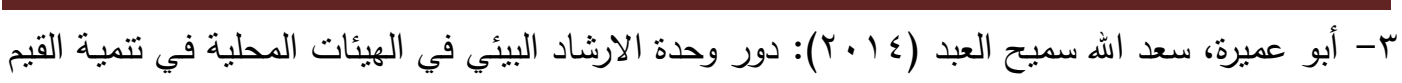

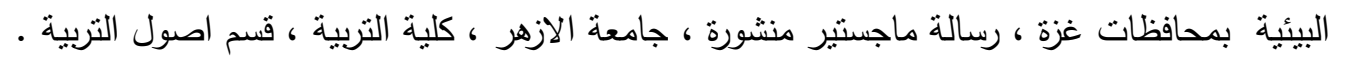

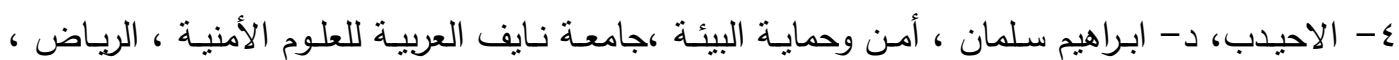

0- بوبيش، فريد ، وبو ترعة، بلال (r ( ب): تلوث البيئة الحضرية والصحة - مقاربة سوسيولوجية، مجلة

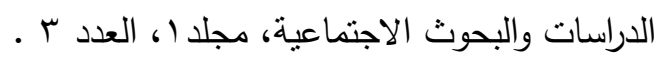

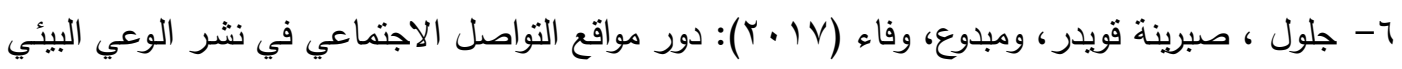

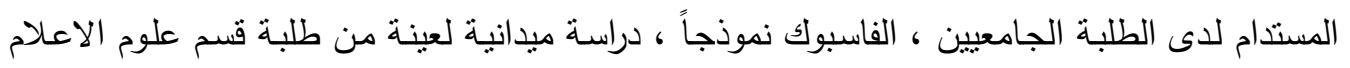

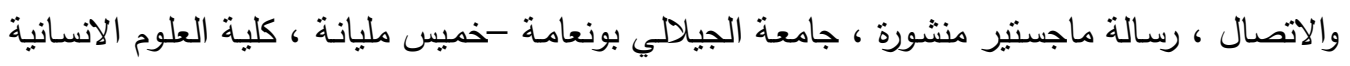

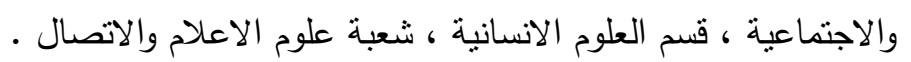

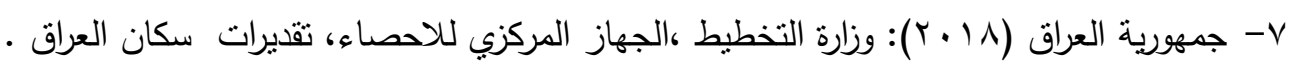

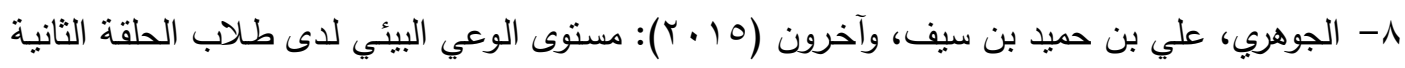

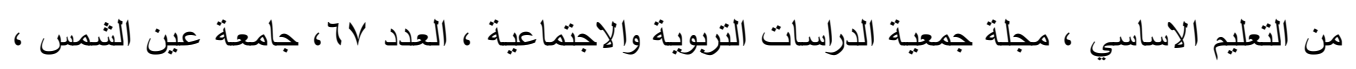

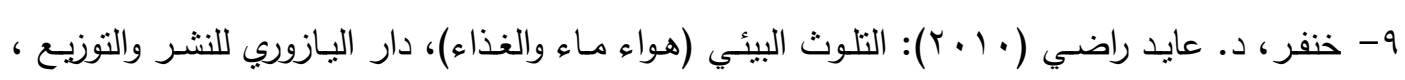

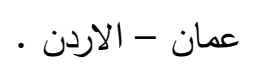

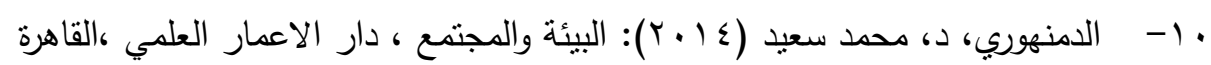

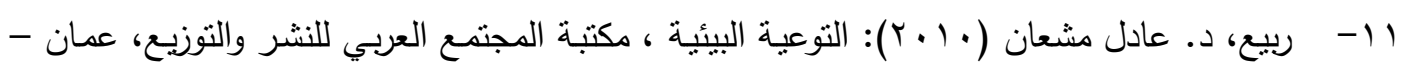
• الاردن

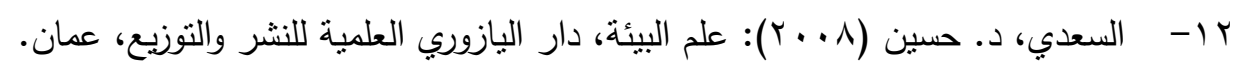

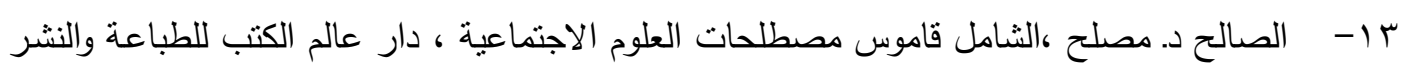

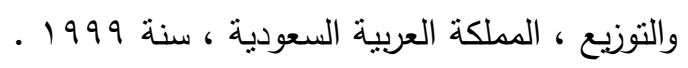

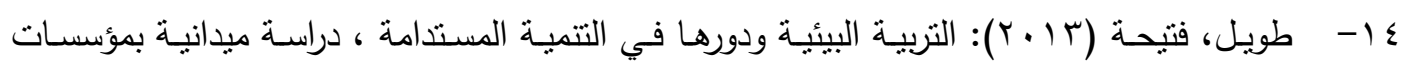
التعليم المتوسط بمدينة بسكرة ، اطروحة دكتوراه، منشورة ، جامعة محمد خضير ، كلية العلوم الانسانية والاجتماعية ، قسم العلوم الاجتماعية ، بسكره، الجزائر ل

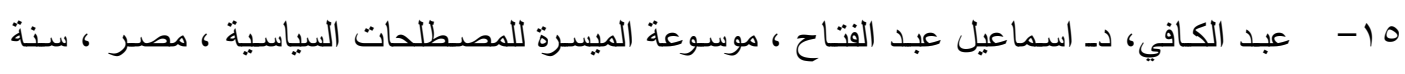

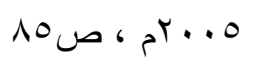

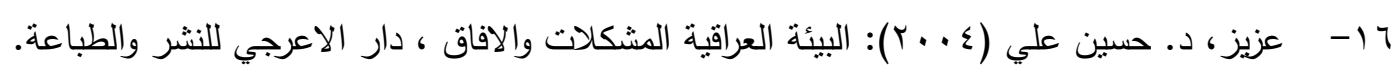

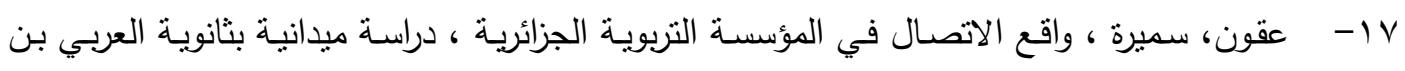

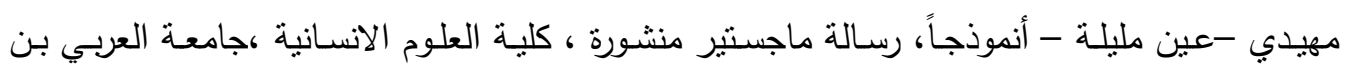

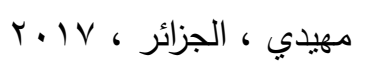

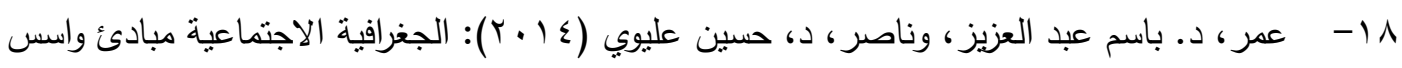

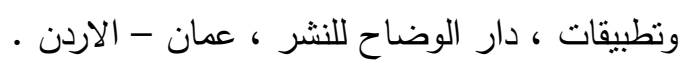

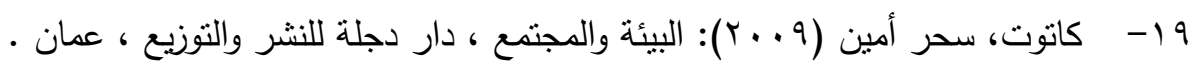




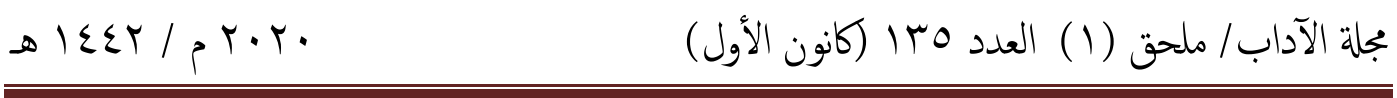

$$
\begin{aligned}
& \text { • ץ- محمد مرتضى بن محمد الحسيني الزبيدي ، تاج العروس من جوهر القاموس ج9 ، طا ، دار }
\end{aligned}
$$

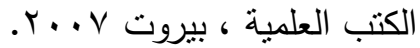

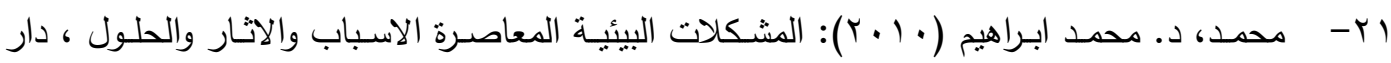

$$
\begin{aligned}
& \text { المعرفة الجامعية للطبع والنشر والتوزيع ، القاهرة . }
\end{aligned}
$$

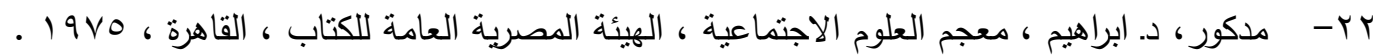

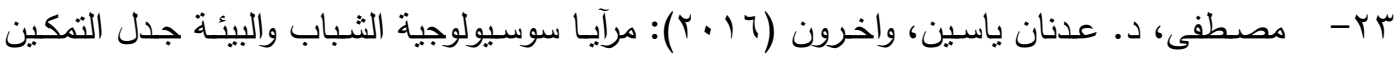

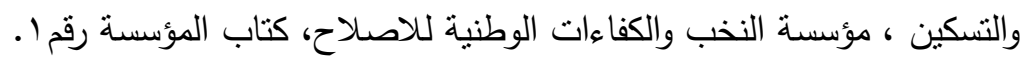

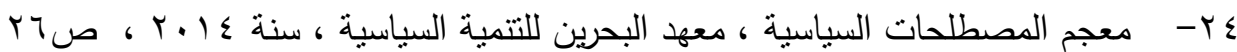

$$
\begin{aligned}
& \text { هץ- منصسور، زينب حبيب ، المعجم البيئي طا ،الناشـر : دار اسـامة للنشر والتوزيـع ، الاردن عمان } \\
& \text {. Y. I16 }
\end{aligned}
$$

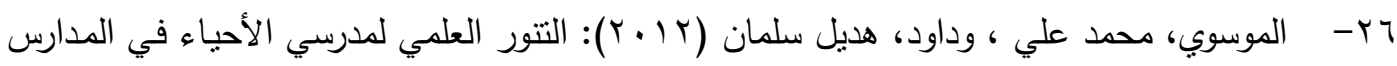

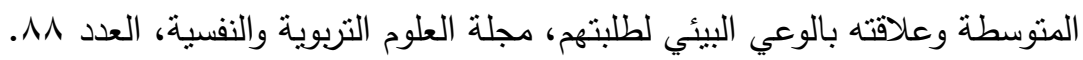

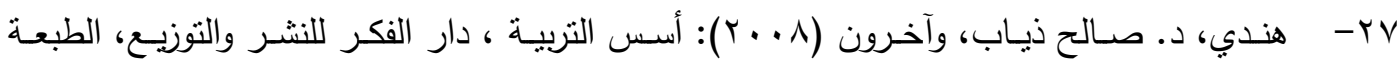

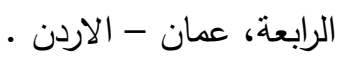

\section{References:}

1- Abu Amira, Saad Allah Samih Al-Abd (2014): The role of the Environmental Guidance Unit in the local authorities in developing environmental values in the governorates of Gaza, a published master's thesis, Al-Azhar University, College of Education, Department of Fundamentals of Education.

2- Abu Sammour, Hassan, and Al-Khatib, Hamed (2006): Geography of Water Resources, Safaa House for Publishing and Distribution, Amman - Jordan.

3- Al -Saadi, d. Hussein (2008): Ecology, Yazuri Scientific Publishing and Distribution House, Amman.

4- Al-Damanhouri, Dr. Mohammed Saeed (2014): Environment and Society, Scientific Construction House, Cairo.

5- Al-Gohary, Ali Bin Hamid Bin Saif and others (2015): The level of environmental awareness among students of the second cycle of basic education, Journal of the Association for Educational and Social Studies, No. 67, Ain Shams University, Egypt.

6- Al-Musawi, Muhammad Ali, Dawood, Hadeel Salman (2012): The scientific enlightenment of biology teachers in middle schools and its relationship to the environmental awareness of their students, Journal of Educational and Psychological Sciences, No. 88.

7- Aziz, Dr. Hussein Ali (2004): The Iraqi Environment, Problems and Prospects, Al-Araji Publishing and Printing House.

8- Bubish, Farid, and Abu Tera'a, Bilal (2013): Urban Environment and Health Pollution - Sociological Approach, Journal of Social Studies and Research, Volume 1, No. 3.

9- Hndian, Dr. Saleh Dhiab, et al. (2008): Foundations of Education, Dar AlFikr for Publishing and Distribution, Fourth Edition, Amman - Jordan.

10- Jalloul, Sabrina Qwaider, Mubadoo, and Wafa (2017): The role of social media in spreading sustainable environmental awareness among undergraduates, Facebook as a model, a field study of a sample of students from the Department of Information and Communication Sciences, a published master's thesis, University 
of Al-Jilali Bonama - Khamis Miliana , College of Humanities and Social Sciences, Department of Humanities, Division of Information and Communication Sciences.

11- Katot, Sahar Amin (2009): Environment and Society, Tigris Publishing and Distribution House, Amman.

12- Khanfar, Dr. Ayed Radi (2010): Environmental pollution (air, water and food), Al-Yazouri House for Publishing and Distribution, Amman - Jordan.

13- Mohammed, Dr. Mohamed Ibrahim (2010): Contemporary Environmental Problems, Impacts and Solutions, University Knowledge House for Printing, Publishing and Distribution, Cairo.

14- Mustafa, Dr. Adnan Yassin, et al. (2016): Mirrors of sociology of youth and the environment. Empowerment and empowerment debate, The Elites and National Competencies for Reform Foundation, Foundation Book No. 1.

15- Omar, D. Basem Abdel Aziz, Nasser, Dr., Hussein Alewi (2014): Social Geography, Principles, Foundations and Applications, Dar Al-Waddah Publishing, Amman - Jordan.

16- Rabee, Dr. Adel Mishaan (2010): Environmental Awareness, Arab Society Library for Publishing and Distribution, Amman - Jordan.

17- Republic of Iraq (2018): Ministry of Planning, Central Statistical Organization, Estimates of the Population of Iraq.

18- Tawil, Fatiha (2013): Environmental Education and its role in sustainable development, a field study at intermediate education institutions in Biskra, PhD thesis, published, University of Mohamed Khodeir, Faculty of Humanities and Social Sciences, Department of Social Sciences, Biskra, Algeria. 
Environmental pollution and the need for environmental awareness

\section{Dr. Mayada Ahmed Abdul Rahman \\ Nawfal Noman Ibrahim \\ University of Baghdad / College of Arts}

\section{Abstract:}

The environment and its problems are of great importance, so environmental issues have imposed themselves on various levels and levels, whether they are local, regional or international.

Which encouraged countries to hold conferences and seminars to put in place laws that limit that risk that threatens all living organisms, including the person who is the primary responsible for these problems, and environmental pollution is a problem of the modern era and one of its most prominent issues that threatens all countries.

The Iraqi reality is not in isolation from this pollution, and what made matters worse the wars that Iraq witnessed, the economic blockade and the collapse of the entire infrastructure, which had negative effects on the Iraqi environment. In this chapter, the first two topics are entitled (environmental awareness), while the second topic (development and environmental awareness).

Key words: pollution, environment, awareness, awareness, human. 